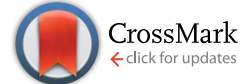

Cite this: RSC Adv., 2014, 4, 65137

Received 8th October 2014

Accepted 18th November 2014

DOI: 10.1039/c4ra11963k

www.rsc.org/advances

\section{Heterogeneous Pd catalysts supported on silica matrices}

\author{
Maksym Opanasenko, ${ }^{a}$ Petr Štěpnička*b and Jiři Čejka*a \\ Palladium catalysts deposited over different types of silica (amorphous silica, mesoporous molecular sieves, \\ solids obtained by co-condensation of silicate precursors and many others) modified with suitable donor \\ moieties have gained enormous importance due to their wide application as catalysts for cross-coupling \\ and other synthetically useful organic reactions. This work provides an overview of the chemistry of \\ silica-supported palladium catalysts in different types of organic transformations in order to present the \\ major features, advantages and limitations of various supports and immobilised ligands.
}

\section{Introduction}

Palladium-catalysed cross-coupling reactions such as Heck, Suzuki-Miyaura, Stille, Sonogashira etc. have gained enormous importance during the last few decades since many valuable products can be efficiently synthesised using these reactions with high efficiency. ${ }^{1}$ In line with current challenges arising from the demands of industrial and fine chemistry, catalysts should exert not only high activity and selectivity to the target products, but they also have to be easily accessible (in terms of their price and synthesis), tolerant to the environment, stable (robust) and recyclable. In view of these requirements, solid catalysts appear to be more suitable for large-scale applications

${ }^{a} J$. Heyrovský Institute of Physical Chemistry, Academy Sciences of the Czech Republic, v.v.i., Dolejškova 3, 18223 Prague 8, Czech Republic. E-mail:jiri.cejka@jh-inst.cas.cz ${ }^{b}$ Department of Inorganic Chemistry, Faculty of Science, Charles University in Prague, Hlavova 2030, 12840 Prague 2, Czech Republic. E-mail: stepnic@natur.cuni.cz than their homogeneous counterparts. Consequently, supported palladium catalysts represent promising targets in catalyst design not only due to their wide applicability in practically important reactions ${ }^{2}$ but also due to their chemical robustness, recyclability, environmental issues as well as economic aspects.

With this regard, silicas fulfil many of the required criteria as suitable solid supports for deposited palladium catalysts. Moreover, silica materials are accessible in a broad variety differing in their structural and textural properties. Besides the commonly encountered amorphous representatives (such as conventional silica), one of the most important and relevant group of siliceous materials relevant to catalysis are mesoporous molecular sieves possessing large surface areas and void volumes. $^{3-5}$ Pore diameters in most of such materials are in the range between two and few tens of nanometres allowing for anchoring of bulky catalytically active species onto the support. The majority of mesoporous materials possess structures of

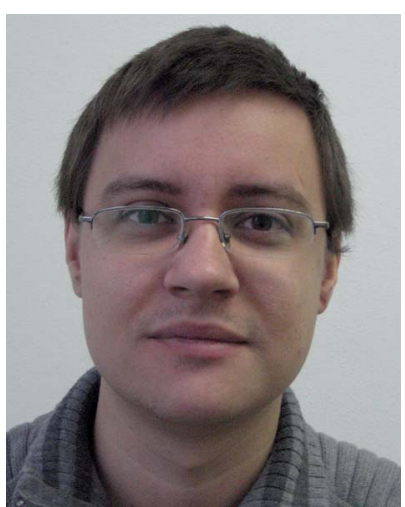

Maksym Opanasenko received his postgraduate degree in chemistry from the Lomonosov Moscow State University in 2006 and later a Ph.D. degree from Pisarzhevsky Institute of Physical Chemistry of the National Academy of Sciences of Ukraine in 2011. Dr Opanasenko has got a postdoctoral position at the Department of Synthesis and Catalysis at the J. Heyrovsky Institute of Physical Chemistry in Prague. His research interests involve synthesis and modification of zeolites, hybrid and hierarchical materials, and application of porous solids in adsorption and catalysis.

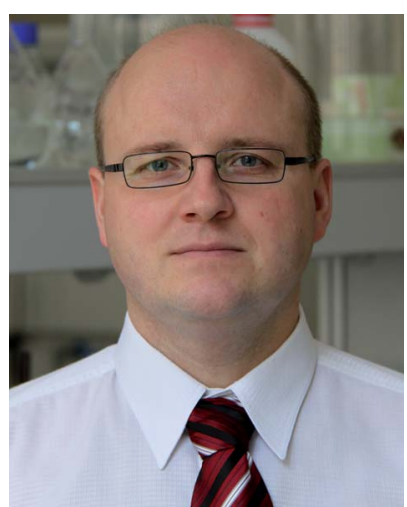

Petr Štěpnička received his master degree in Chemistry from Charles University in Prague in 1995 and, in 1998, completed his Ph.D. at the same institution. After a postdoctoral stay at Catalysis Research Center, Hokkaido University in Sapporo, he returned to his alma mater, where he was promoted to Associate Professor in 2005 and Full Professor of Inorganic Chemistry in 2012. His main research interests include the design of new phosphinoferrocene donors for applications in coordination chemistry and catalysis and the preparation of deposited palladium catalysts. 
hexagonal (MCM-41, ${ }^{6} \mathrm{SBA}-15,{ }^{7} \mathrm{FSM}-16$ (ref. 8)) or cubic (MCM$48,{ }^{9} \mathrm{KIT}-6,{ }^{10} \mathrm{SBA}-16$ (ref. 11)) symmetry. In terms of porosity, the materials include those with disordered structures but uniform pore sizes (e.g. HMS, ${ }^{12}$ TUD-1, ${ }^{13}$ MSU $^{14}$ etc.), mesoporous solids with (SBA-2, SBA-12, SBA-16) or without (SBA-15, MCM-48) large cages, and materials that also contain micropores in the walls of the mesopores (e.g. in SBA-15, ${ }^{15}$ KIT-6 (ref. 16)). Several mesoporous materials with similar symmetry can be viewed as smallmesopore and large-mesopore analogues, although they have been synthesised using different procedures. The examples are hexagonal MCM-41 (pore size in the range 1.5-10 nm (ref. 17)) and SBA-15 (3.6-30 nm (ref. 18 and 19)), or cubic MCM-48 (1.6$4.2 \mathrm{~nm}$ (ref. 20 and 21)) and KIT-6 (8-10 nm (ref. 22)). Yet another group of silica-based materials, which are potentially applicable as supports, is constituted by delaminated zeolitic materials, such as ITQ-2 (ref. 23) and ITQ-6, ${ }^{24}$ representing the so-called two-dimensional zeolites..$^{25,26}$ This structural diversity together with favourable chemical properties (stability, chemical inertness, accessibility to functional modifications etc.) render these materials very attractive for catalyst design as the basic critical parameters - overall structure and diameter of the pores - can be adjusted on purpose.

Mesoporous molecular sieves based on silica or alumina are hydrothermally unstable at high reaction temperatures and also lack active sites, which in turn limit their potential for direct catalytic applications. On the other hand, the possibility to modify silica supports with different reagents allows the anchoring of various functional moieties and thus the preparation of active catalysts for a number of reactions. ${ }^{27-32}$ Furthermore, textural features of mesoporous molecular sieves offer a large potential for the direct or post-synthetic modification, such as the incorporation of active centres, grafting or immobilization of active species including metal complexes or organometallic substrates.

In addition to silica, other types of supports can be used for anchoring of the Pd-complexes including metal-organic frameworks, ${ }^{33-35}$ magnetic supports, ${ }^{36-39}$ carbons, ${ }^{1,40-42}$ and polymers. ${ }^{43-45}$ However, the mentioned solids can possess such drawbacks as relatively low stability (metal-organic

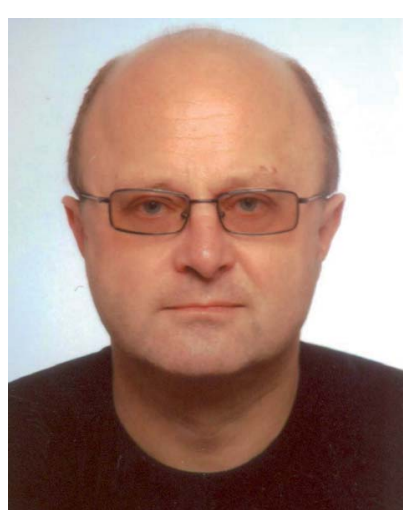

Prof. Jiři Čejka was born in Roudnice nad Labem, former Czechoslovakia, in 1960. At present he is a head of the Department of Synthesis and Catalysis at the J. Heyrovský Institute of Physical Chemistry in Prague and is lecturing the courses on catalysis at the Faculty of Science, Charles University in Prague. His research interests comprise: synthesis of zeolites, mesoporous, and novel nanostructured materials, physical chemistry of sorption and catalysis, and investigation of the role of porous catalysts in transformations of hydrocarbons and their derivatives. frameworks, activated carbons), lack of structural variability (magnetic nanoparticles) or restrictions for reuse (carbons, polymers). Therefore, owing to favourable properties (accessibility, stability, recyclability, variability and generally low prize), silicas seem to be one of the most promising materials for applications as solid supports.

Since silica-based catalysts are mainly utilised in liquidphase reactions, covalent bonding between the active species and the support surface is favoured in order to minimise the undesired leaching of the anchored groups and metal. There have been established several approaches towards the preparation of supported Pd-catalysts (Scheme 1). In general, the functional modification can be performed in one or several separate steps. In the one-step procedure, the substrate containing both the anchoring group (able to participate in the condensation with the surface silanol groups) and functional group linked to the metal must be assembled prior to the grafting onto the support. This method usually provides better defined materials with well-distributed active centres but can be complicated by undesired processes, e.g., interactions of the anchoring moiety with the precursor of the active component or, simply, by a difficult preparation of the precursor to be immobilised. If the multi-step procedure is employed, the selected support is firstly covalently modified with a functional reagent possessing the combination of an anchoring moiety and a functional group able to interact with the active catalyst component or another reagent used to construct metal-binding groups. After the modification of the support surface (and possible creation of the suitable functional group), the material is loaded with the respective metal precursor. The main drawback of this approach lies in the lack of control of the interaction between the active component and the modified support. The preparation of silica supports containing functional groups (either with the metal or not) can be performed either postsynthetically (grafting) or by direct synthesis using cocondensation method (Scheme 1).

The most frequently used modifying agent for either postsynthetic modification or co-condensation is (3-aminopropyl) triethoxysilane (APTES), which is commercially available and comprises both the anchoring (alkoxysilyl) and functional (amino) groups. However, it should be born in mind that the condensation reactions of APTES as well as other trialkoxysilanes need not necessarily proceed completely (e.g., for steric reasons) and the resulting materials thus typically contain nonhydrolyzed SiOR moieties and unreacted $\mathrm{SiOH}$ groups at the support surface. ${ }^{46}$

Importantly, the terminal amine group makes APTES a good entry towards other functional moieties (Fig. 1). In particular, the simplest set of these APTES-derived (directly of formally) modifiers is represented by linear or branched aliphatic aminocontaining groups. Because of its simplicity and versatility, such substances have been widely used for immobilization of palladium species. Already in 1974, Capka et al. prepared immobilised metal (Rh, Pt and Pd) catalysts by treatment of donorfunctionalised inert supports (in particular, silica) with [3(dimethylamino)propyl]triethoxysilane and other anchoring groups. ${ }^{47}$ Later, Sharf et $a .^{48}$ reported the preparation of 


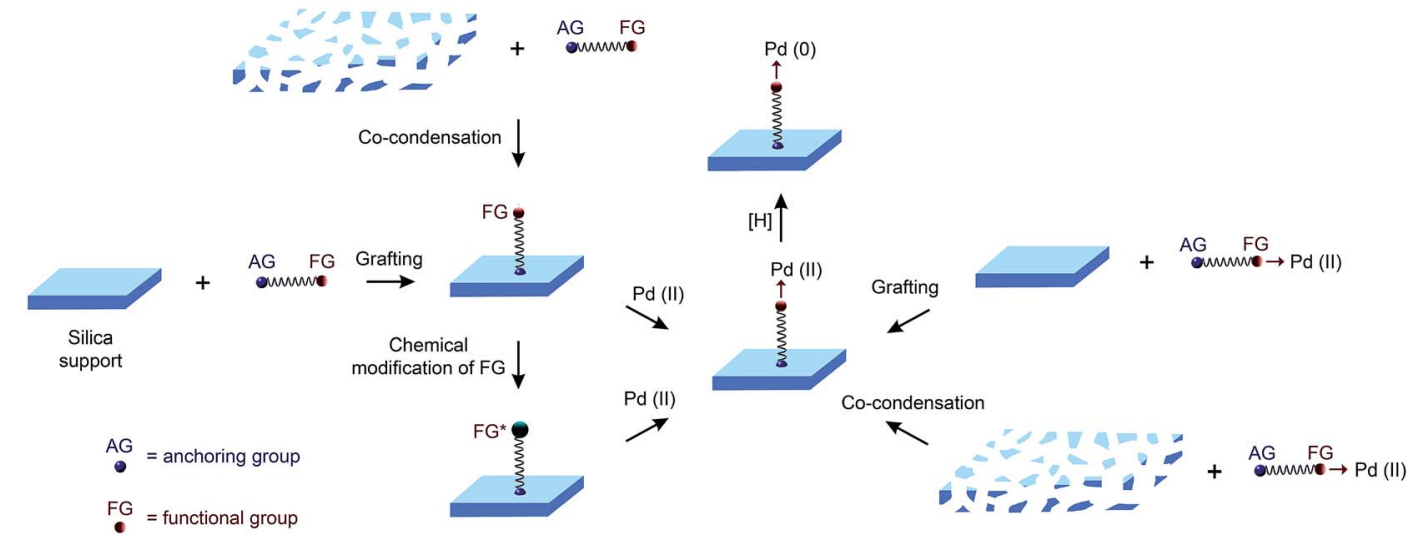

Scheme 1 One-step (right) and multi-step (left) routes to supported Pd-catalysts using post-synthetic (grafting) and direct (co-condensations) ways for the formation of the support.

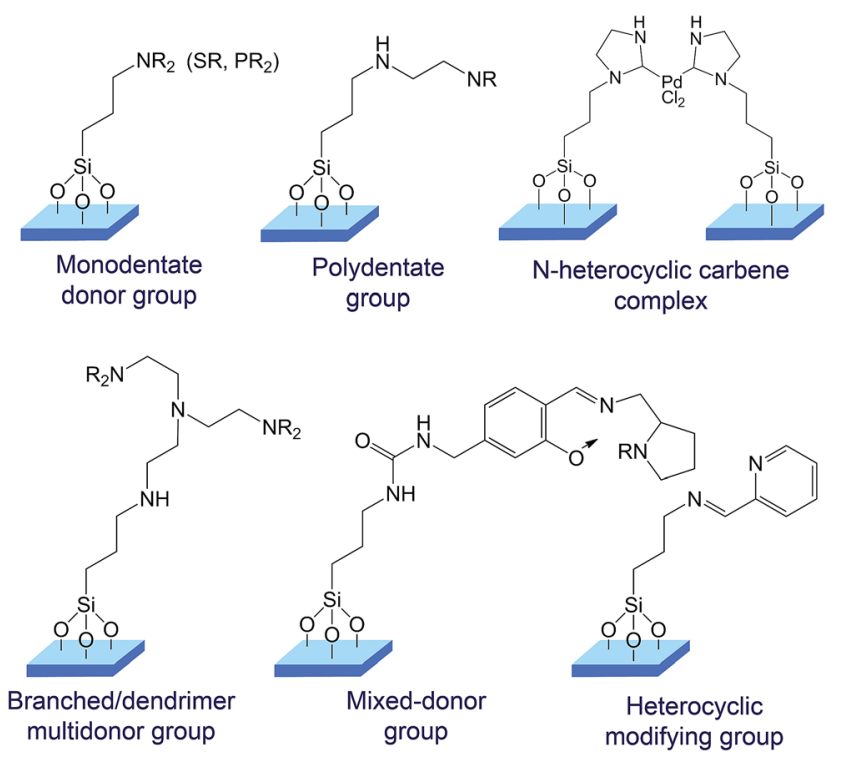

Fig. 1 Examples of different types of anchoring groups utilised for the preparation of supported Pd catalysts.

$\omega$-aminoalkyl modified supports by treatment of the conventional silica gel with $\mathrm{H}_{2} \mathrm{~N}\left(\mathrm{CH}_{2}\right)_{n} \mathrm{Si}(\mathrm{OEt})_{3}(n=1,3)$, and their subsequent metalation with $\mathrm{Na}_{2}\left[\mathrm{PdCl}_{4}\right]$. Even polymeric aminoalkyl chain can be grafted onto the silica support as it was recently reported. ${ }^{49,50}$ Nowadays, the materials containing linear or branched aliphatic amino-containing groups (Fig. 1) with anchored Pd are mainly utilised as catalysts for the Heck, Suzuki-Miyaura and other cross-coupling reactions. ${ }^{1}$

Another type of successfully employed surface functional groups belongs to heterocyclic ones (N-heterocyclic in particular; Fig. 1). Supported catalysts possessing N-heterocyclic anchoring groups are mainly represented by materials bearing iminopyridyl (and similar heteroaryl-imino) substituents resulting by condensation of surface-bound 3-aminopropyl groups with 2-pyridinecarbaldehyde or other heterocyclic aldehydes. ${ }^{51}$ In general, other N-heterocyclic moieties can be used for metal anchoring ${ }^{52,53}$ but they are relatively less commonly used for the preparation supported Pd catalysts. A number of different immobilised N-heterocyclic carbene (NHC) donors (Fig. 1) have been used for the anchoring of palladium resulting in the formation of highly active NHC-Pd catalysts for $\mathrm{C}-\mathrm{C}$ bond coupling and other types of reactions. ${ }^{54-56}$ Recently, we have demonstrated that the aminopropyl groups at the surface are accessible also for conventional amidation reactions with functional carboxylic acids in the presence of peptide coupling agents. ${ }^{57,58}$ The resulting functional supports containing the $\equiv \mathrm{Si}\left(\mathrm{CH}_{2}\right)_{3} \mathrm{NHCOCH}_{2} \mathrm{Y}\left(\mathrm{Y}=\mathrm{NMe}_{2}\right.$, SMe and $\left.\mathrm{PPh}_{2}\right)$ mixed-donor ligating groups were used to immobilise palladium and the catalysts were evaluated in various $\mathrm{C}-\mathrm{C}$ bond forming reactions. ${ }^{59,60}$

Besides the N-based anchoring modifiers, other donor groups (such as S-, P-, As-containing) can be also used. In this regard, sulphur-containing modifying groups, particularly those bearing terminal mercapto substituents, are among the most frequently utilised. Shimizu et $a l^{61}$ reported the preparation of an SH-functionalised mesoporous silica FSM-16 by treatment with (3-mercaptopropyl)triethoxysilane. A material based on amorphous silica was obtained by hydrolysis/ condensation reaction of the same mercapto precursor with tetraethyl orthosilicate (TEOS). The sulphur ligands in the sizerestricted mesopores of FSM-16 were the most effective for preventing aggregation of Pd species, which in turn resulted in a high durability and good recycling characteristics of the prepared supported catalysts. ${ }^{61}$ The interest in new catalysts deposited on solid supports equipped with phosphine donor moieties was undoubtedly stimulated by analogies with highly efficient homogeneous (molecular) transition metal-phosphine catalysts. ${ }^{62-64}$ However, the catalysts containing phosphine ligands are often unstable at higher temperatures and the procedures for their preparation are rather complicated since the synthesis of the phosphine ligands requires multi-step reactions sequences and an exclusion of possible oxidants (or temporary protection of the phosphorus centre). ${ }^{65,66}$ As an example of an As-containing catalyst can serve silica-supported poly-[3-(diphenylarsino)propyl]siloxane-palladium complex prepared via immobilization of (3-chloropropyl)triethoxysilane 
on fumed silica, followed by treatment with potassium diphenylarsenide and then a palladium source. ${ }^{67}$ Most of the aforementioned supported materials bearing different types of donor groups exhibited high efficiency in cross-coupling reactions and could be recovered and reused. ${ }^{68}$ In addition to examples mentioned before, there are many reports dealing with the preparation of supported catalysts modified with multidonor moieties (as an example, see Fig. 1) consisting of several donor atoms in positions allowing for chelate coordination. ${ }^{69,70}$

Recent reports ${ }^{71,72}$ have been devoted to the investigation of in situ transformations of palladium precatalysts before and during the catalytic reaction in order to elucidate the nature of the true active species in coupling reactions. It was established, that one of the most important parameters influencing the nature of the true form of the catalyst is the temperature, at which the system operates. Donor ligands (N-, S-, P-based) can be indeed a component of truly active, soluble palladium complexes in reactions like Heck or Suzuki-Miyaura coupling. However, reaction conditions, under which such ligands can influence the catalysis, are usually limited to temperatures below $80{ }^{\circ} \mathrm{C} .{ }^{71}$ At temperatures above $120{ }^{\circ} \mathrm{C}$, the palladium catalyst is rapidly reduced to $\operatorname{Pd}(0)$ having a strong tendency to form soluble colloids. ${ }^{72}$ After completion of the reaction cycle, Pd may participate in the next catalytic cycle or return to the colloidal system. When solid-supported $\operatorname{Pd}(0)$ particles were used, it was reported that the activity is associated with leached palladium species derived from the metal particles. ${ }^{73}$ After reaction, the "soluble palladium" was often observed to redeposit on the solid support. ${ }^{74}$ In some cases, it has been suggested that the reaction occur on the palladium metal surface ${ }^{75,76}$ however no clear evidences have been presented that confirm the exceptional participation of palladium surface as true catalytic sites.

Although many catalytic systems were assumed to operate via mechanism involving the $\mathrm{Pd}(\mathrm{II})-\mathrm{Pd}(\mathrm{Iv})$ couple, there are no unambiguous data corroborating the involvement of this catalytic cycle in coupling reactions such as Suzuki-Miyaura, Heck or Sonogashira. ${ }^{77-79}$ The various reactions that potentially could proceed through the $\operatorname{Pd}(\mathrm{II})-\mathrm{Pd}(\mathrm{Iv})$ mechanism have been consistently shown to proceed via a traditional $\operatorname{Pd}(0)-\operatorname{Pd}(\mathrm{II})$ cycle. $^{71}$

The aim of this review is to provide an insight into the stateof-the-art in the field of the application of silica-supported palladium catalysts in different types of reactions (crosscoupling, carbonylation/carboxylation, redox processes etc.). Features, advantages and limitations associated with the various supports and ligating groups are discussed. The article is organised with respect to the reactions in which the catalyst were employed so as to allow for a comparison of different approaches towards the design of catalysts for a particular type of organic transformation, covering the literature up to 2014 . Although many examples of $\mathrm{C}-\mathrm{N}, \mathrm{C}-\mathrm{O}$ and $\mathrm{C}-\mathrm{S}$ coupling reactions catalysed by $\mathrm{Pd}$ anchored to solid supports have been reported, ${ }^{\mathbf{8 0}-\mathbf{8 3}}$ the $\mathrm{C}-\mathrm{C}$ couplings still remain the main topic of interest at the moment. Hence, the main part of this review is devoted to $\mathrm{C}-\mathrm{C}$ bond forming reactions though various $\mathrm{C}-\mathrm{X}$ $(\mathrm{X}=\mathrm{O}, \mathrm{N}, \mathrm{S})$ couplings are also mentioned as they result in the formation of valuable functional molecules such as amides, esters, heterocyclic compounds, etc.

\section{Heck coupling}

The reaction of alkyl- or aryl-substituted alkenes containing at least one hydrogen atom at the $\mathrm{C}=\mathrm{C}$ double bond with aryl, benzyl, and vinyl halides or triflates, which proceeds under the formation of new $\mathrm{C}-\mathrm{C}$ bond and affords a substituted alkene, is known as the Heck coupling (or Mizoroki-Heck reaction; Scheme 2). It is generally catalysed by palladium species generated in situ from various $\mathrm{Pd}(\mathrm{II})$ salts or complexes and requires bases (organic or inorganic) to neutralize the acid HX formed during the reaction. ${ }^{84} \mathrm{~A}$ wide range of functional groups, both in the alkene and in the halide, is compatible with the Heck coupling, ${ }^{84}$ which renders the reaction synthetically robust and thus practically widely applicable. Mechanism of the Heck reaction is still a matter of debate because it is not yet fully evidenced whether the $\mathrm{Pd}(0) / \mathrm{Pd}(\mathrm{II})$ or the $\mathrm{Pd}(\mathrm{II}) / \mathrm{Pd}(\mathrm{IV})$ redox couple is involved in the catalytic cycle. ${ }^{85-87}$ One of the major drawbacks of the early catalytic systems was the precipitation of palladium black that limited the lifetime of the active species and, thereby, the overall catalytic efficacy. Consequently, numerous attempts have been made to circumvent these limitations by the development of new active molecular catalysts as well as through anchoring of the Pd species onto solid supports.

For instance, Zhu et al. ${ }^{88}$ prepared a series of $\operatorname{Pd}(0)$ catalysts deposited over anilino- and pyridylamino-modified silica gel. These catalysts performed very well in Heck coupling of iodobenzene with styrene or acrylamide (TON up to $c a .17$ 000), being recyclable without a loss of activity.

Clark and co-workers reported the preparation of mesoporous silica gel modified by iminopyridine groups via the reaction of aminopropylated silica with 2-pyridinecarbaldehyde. These supports were subsequently metallated with a palladium(II) salt. The resulting materials proved to be active and reusable catalysts for Heck coupling of iodobenzene and methyl acrylate. ${ }^{89}$ High catalytic activity of these catalyst generated considerable controversy, since the palladium was immobilised in the + II oxidation state, which raised questions about the mechanism of the coupling reaction and the possibility of the involvement of the $\mathrm{Pd}(\mathrm{II}) / \mathrm{Pd}(\mathrm{Iv})$ couple in the catalytic cycle.

In order to obtain supported $\operatorname{Pd}(0)$ catalyst for the Heck reaction, Zhou and co-workers ${ }^{90}$ grafted mesoporous sieve MCM-41 by (EtO) $)_{3} \mathrm{Si}\left(\mathrm{CH}_{2}\right)_{3} \mathrm{NH}_{2}$ and then treated the modified support with $\mathrm{PdCl}_{2}$ and reduced the deposited $\operatorname{Pd}(\mathrm{II})$ to $\operatorname{Pd}(0)$

$$
\begin{aligned}
& \mathrm{R}=\mathrm{Ar}, \mathrm{Bn}, \mathrm{vinyl} \\
& \mathrm{R}^{\prime}=\mathrm{H}, \mathrm{Alk}, \mathrm{Ar} \text {, COOAlk } \\
& \mathrm{X}=\mathrm{Cl}, \mathrm{Br}, \mathrm{I}, \mathrm{OTf}
\end{aligned}
$$

Scheme 2 The Heck coupling reaction. 
with $\mathrm{Na}\left[\mathrm{BH}_{4}\right]$. The resulting catalyst efficiently promoted Heck coupling of substituted iodobenzenes and activated alkenes with yields up to $98 \%$ (TOF was in the range of $60-160 \mathrm{~h}^{-1}$ ). The catalyst exhibited unchanged efficiency after a prolonged exposure to air and could be recycled at least two times without any significant loss of activity.

Later on, Zhou et al. used a series of amine- $\operatorname{Pd}(0)$ complexes deposited on fumed silica surface modified with the $\equiv \mathrm{Si}\left(\mathrm{CH}_{2}\right)_{3} \mathrm{NR}_{2}$ groups $(\mathrm{R}=\mathrm{H}$, Et, $\mathrm{Bu})$ in the same reaction. ${ }^{91}$ The catalysts exhibited comparably high yields, which quite significantly depended on the nature of the solvent used. With the decrease in solvent polarity in the series DMF > EtOH > $\mathrm{CH}_{3} \mathrm{CN}>\mathrm{C}_{6} \mathrm{H}_{12}$, the yield of the coupling product in the reaction of iodobenzene and acrylic acid over catalyst with $\mathrm{R}=\mathrm{H}$ decreased as follows $99.1>90.5>88.9>83.2 \%$. However, for other catalysts this dependence was not monotonous indicating that the influence of the polarity of solvent is not straightforward and general in this case.

Wang et al. ${ }^{92}$ have shown that $\operatorname{Pd}(0)$ immobilised on conventional silica gel modified with $\equiv \mathrm{Si}\left(\mathrm{CH}_{2}\right)_{3} \mathrm{NH}_{2}$ or $\equiv \mathrm{Si}\left(\mathrm{CH}_{2}\right)_{3} \mathrm{NH}\left(\mathrm{CH}_{2}\right)_{2} \mathrm{NH}_{2}$ groups behaves as an active and recyclable catalyst in the Heck reaction of iodoarenes, bromoarenes, and even activated chloroarenes.

Demel et al. studied the relation between the nature of the nitrogen modifying group and the catalytic activity as well as the amount of leached metal in the Heck reaction over $\operatorname{Pd}(0)$ immobilised on mesoporous molecular sieves SBA-15 and MCM-48 performed under conventional (solvothermal) conditions as well as under microwave irradiation. ${ }^{93}$ Among the catalysts modified with different alkylamino groups, the best properties in terms of activity and stability were exerted by those possessing the $\equiv \mathrm{Si}\left(\mathrm{CH}_{2}\right)_{3} \mathrm{NH}_{2}$ and $\equiv \mathrm{Si}\left(\mathrm{CH}_{2}\right)_{3} \mathrm{NH}\left(\mathrm{CH}_{2}\right)_{2} \mathrm{NEt}_{2}$ groups. In contrast, material possessing the branched multidonor $\equiv \mathrm{Si}\left(\mathrm{CH}_{2}\right)_{3} \mathrm{NH}\left(\mathrm{CH}_{2}\right)_{2} \mathrm{~N}\left(\left(\mathrm{CH}_{2}\right)_{2} \mathrm{NH}_{2}\right)_{2}$ groups proved to be catalytically inactive and could be even used as an efficient catalytic poison (metal scavenger). It was concluded that not only the number of nitrogen atoms in the anchoring group but rather their type is the decisive factor controlling the stabilization (and availability) of the metal component in the reaction system.

A follow-up study on the influence of the metal loading (and $\mathrm{Pd} / \mathrm{N}$ molar ratio) in SBA-15 sieve modified with the $\equiv \mathrm{Si}\left(\mathrm{CH}_{2}\right)_{3} \mathrm{NH}\left(\mathrm{CH}_{2}\right)_{2} \mathrm{NEt}_{2}$ groups (Fig. 2) revealed an increase in the yield of $n$-butyl cinnamate in the Heck reaction of bromobenzene and $n$-butyl acrylate upon decreasing the $\mathrm{Pd} / \mathrm{N}$ ratio in the catalysts. ${ }^{94}$ As the Heck reaction over supported palladium catalysts typically takes place in solution with the metal firstly leaching out from the support and then returning back to the solid matrix, the observed trend was explained by a lower accessibility of the palladium for the organic reagents when the donor nitrogen groups are present in a large excess.

In contrast, Wang et al. ${ }^{95}$ found a non-monotonous dependence of the catalytic activity and $\mathrm{Pd}$ leaching on the $\mathrm{Pd} / \mathrm{N}$ molar ratio in SBA-15 sieve modified with the $\equiv \mathrm{Si}\left(\mathrm{CH}_{2}\right)_{3} \mathrm{NH}\left(\mathrm{CH}_{2}\right)_{2} \mathrm{NH}_{2}$ groups using the model coupling reaction of iodobenzene and acrylic acid. Catalyst having $\mathrm{Pd} / \mathrm{N}$ ratio of $2: 1$ showed moderate leaching $(0.1 \mathrm{ppm})$ at the highest yield of the target product ( $c f$.

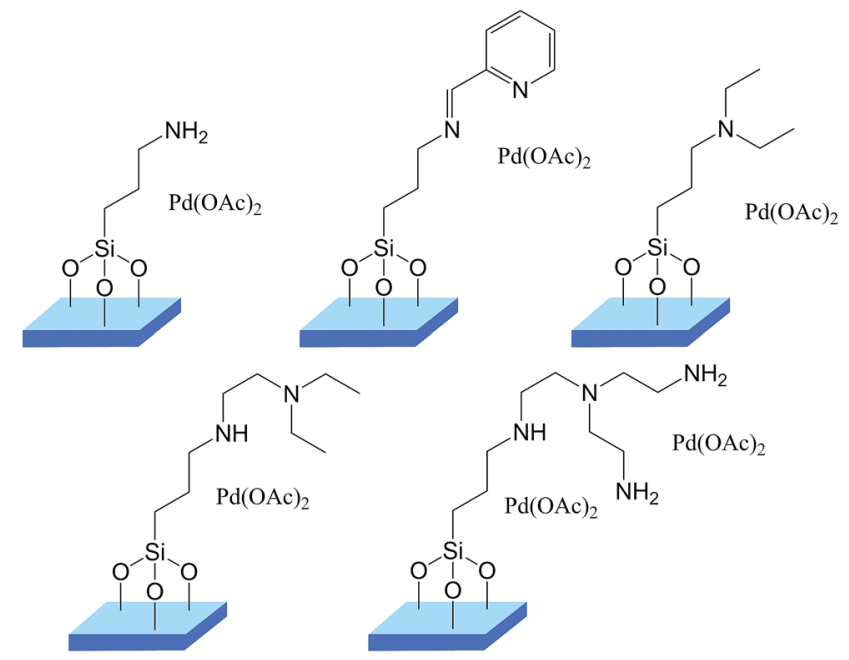

Fig. 2 Supported Pd-catalysts comparatively evaluated in Heck coupling

the yields of $98 \%$ vs. 59 and $86 \%$ for catalysts with $\mathrm{Pd} / \mathrm{N}$ ratio $2: 1,4: 1$ and $1: 1$, respectively)..$^{95}$

More recently, it was demonstrated that the nature of the support (amorphous silica vs. mesoporous molecular sieve SBA-15) only insignificantly affects the catalytic performance of $\operatorname{Pd}(0)$ supported catalysts modified with $\equiv \mathrm{Si}\left(\mathrm{CH}_{2}\right)_{3} \mathrm{NH}\left(\mathrm{CH}_{2}\right)_{2} \mathrm{NEt}_{2}$ groups in the Heck reaction of $n$-butyl acrylate with bromobenzene. ${ }^{96}$ Slightly higher conversions achieved over amorphous silica-based catalysts were due to a better availability of the active metal in this support. The role of mesopores was assumed to be limited only to altering the rate of diffusion of palladium species into the liquid phase (leaching).

Vallribera et al. have proposed the method of preparation of silica aerogels doped with Pd nanoparticles based on cohydrolysis of tetraethoxysilane (TEOS) and organofunctional alkoxysilanes of the type $\left(\mathrm{CH}_{3} \mathrm{O}\right)_{3} \mathrm{Si}\left(\mathrm{CH}_{2}\right)_{3} \mathrm{~A}$, where $\mathrm{A}$ is a potential donor group, subsequent reaction with a $\mathrm{Pd}(\mathrm{II})$ salt. ${ }^{97}$ The obtained materials were tested in the Heck reaction of iodobenzene with ethyl acrylate, styrene and methyl vinyl ketone and compared with carbon aerogels loaded with Pd. In general, silica-based catalysts were found to be more active and stable. For example, the reaction of iodobenzene with ethyl acrylate was complete after $8 \mathrm{~h}$ using $\mathrm{Pd} / \mathrm{SiO}_{2}$ aerogel catalyst, which could be reused three times. Reactions in the presence of $\mathrm{Pd}$-carbon aerogel catalyst required longer reaction times (24 h) to achieve similar results (up to $100 \%$ conversion). A better dispersion of the metal through silica matrix achieved during sol-gel process rendering the aggregation of the Pd particles more difficult was proposed as possible explanation of these results.

Mandal et al. ${ }^{98}$ entrapped Pd and Pt nanoparticles on the surface of micrometer-sized zeolite NaY particles functionalised with the $\equiv \mathrm{Si}\left(\mathrm{CH}_{2}\right)_{3} \mathrm{NH}_{2}$ groups. The synthesised materials were shown to be highly active and recyclable catalysts for the Heck coupling of iodobenzene with styrene to give a mixture of cis- and trans-stilbene (conversions ca. 95\% in 1-3 runs; 
TOF $\approx 1900 \mathrm{~h}^{-1} ;$ cis/trans ratio $\left.c a .10: 90\right)$. The high activity of the catalysts was attributed to an efficient stabilization of the metal nanoparticles on the zeolite surface preventing their aggregation and providing sufficient accessibility of the active centres for the reactants.

In the field of catalyst containing sulphur donor moieties, Martra et $a .^{99}$ found that thiourea groups $\operatorname{PhNHC(S)}$ $\mathrm{NH}\left(\mathrm{CH}_{2}\right)_{3} \mathrm{Si} \equiv$ tethered to silica can reduce $\mathrm{Pd}$ (II) ions to afford Pd nanoparticles of about $2 \mathrm{~nm}$ in size that behave as a good catalyst in the Heck reaction of iodo- and bromoarenes with $n$ butyl acrylate. However, a progressive decrease in the yield of the coupling product took place upon recycling of this material due to a significant leaching. Improvement of the catalytic performance, namely a higher activity at a negligible leaching of active species, was achieved through calcination at $500{ }^{\circ} \mathrm{C}$ that altered not only the size of the particles and the removal of organic residua but, more importantly, changed the surface structure of the supported particles.

High and reproducible catalytic activity and significantly lower leaching of metal species from SBA-15 functionalised with $\equiv \mathrm{Si}\left(\mathrm{CH}_{2}\right)_{3} \mathrm{SH}$ groups in comparison with aminopropylated counterparts ( 3 ppb vs. 35 ppm of Pd) was observed by Crudden et al. ${ }^{\mathbf{1 0 0}}$ The authors noticed an excellent metal scavenging effect of the mercaptopropylated support overcoming that of the related aminopropylated material. ${ }^{101}$ Supportive information on the structure of these catalysts, e.g., about the oxidation state of the deposited palladium and its electronic environment, was inferred from X-ray photoelectron and X-ray Auger spectroscopic measurements. ${ }^{102}$ Increasing leaching of Pd species with increasing $\mathrm{S}: \mathrm{Pd}$ ratio in SBA-15 functionalised with $\equiv \mathrm{Si}\left(\mathrm{CH}_{2}\right)_{3} \mathrm{SH}$ groups in the Heck reaction of styrene with bromoacetophenone was described by the same authors, ${ }^{103}$ being rationalised by increased mobility of the Pd species at lower concentrations of the ligating groups.

MCM-41-supported poly[(3-mercaptopropyl)siloxane palladium(0)] complex was shown to be highly active and stereoselective catalyst for the Heck arylation of conjugated alkenes with less reactive bromoarenes; the catalyst was reused at least five times without a loss of activity. ${ }^{104}$ Similar MCM-41-based materials obtained by functionalization of silica support with the $\equiv \mathrm{Si}\left(\mathrm{CH}_{2}\right)_{3} \mathrm{SH}$ groups, followed by treatment with palladium chloride and reduction using $\mathrm{K}\left[\mathrm{BH}_{4}\right]$ were tested in the Heck reaction of aryl iodides with acrylic acid, methyl acrylate and styrene, achieving yields higher than $80 \%$ and long-term stability. ${ }^{105}$

Cai and co-workers ${ }^{\mathbf{1 0 6}}$ firstly synthesised MCM-41-supported thioether-palladium(0) complex by immobilization of [3-(2cyanoethylsulfanyl)propyl]triethoxysilane, reacting with palladium chloride and subsequent reduction with hydrazine hydrate. The prepared material showed high activities and stereoselectivity in the Heck coupling of conjugated alkenes with aryl iodides and activated aryl bromides. It also efficiently catalysed the arylation of conjugated alkenes with non-activated bromoarenes. Increasing amount of palladium catalyst was shown to shorten the reaction time, but did not increase the yield of the target alkenes.
A fluorous organic-inorganic hybrid material (Fig. 3) was prepared by sol-gel condensation between a monosilylated fluorous precursor and a large excess of TEOS and used as a support for $\operatorname{Pd}(0)$ nanoparticles (diameter $4 \pm 1 \mathrm{~nm}$ ). The resulting material proved to be active in the Heck reaction of iodobenzene with butyl acrylate. ${ }^{\mathbf{1 0 7}}$ However, the authors did not investigate whether the $\operatorname{Pd}(0)$ nanoparticles on the solid surface are the actual catalysts or just represent the source of catalytically active species for the reaction occurring in the liquid phase. The same authors demonstrated that the amount of catalytically active $\operatorname{Pd}(0)$ nanoparticles depends on the number of the long perfluoroalkyl chains in the fluorous organic-inorganic matrix. The bis-silylated compound possessing two anchoring groups, 2,4-bis[3-(triethoxysilyl)propylamino]-6- $S\left(\mathrm{CH}_{2}\right)_{2} \mathrm{C}_{8} \mathrm{~F}_{17} R$-1,3,5-triazine, allowed to increase the $\operatorname{Pd}(0)$ content from 4 to $13 \%$ and to carry out the catalytic Heck reaction with a lower quantity of solid material in the reaction mixture. ${ }^{108}$

$\operatorname{Pd}(0)$ deposited on MCM-41 silica matrix bearing amino and phosphinoalkoxy groups was prepared by immobilization of APTES on the solid support, subsequent reactions with (diphenylphosphino)methanol and palladium chloride and reduction with hydrazine hydrate. Similarly to MCM-41supported poly[(3-mercaptopropyl)siloxane palladium(0)] complex obtained earlier, this Pd catalyst deposited over phosphino-functionalised MCM-41 was an active and stereoselective catalyst for the Heck arylation of conjugated alkenes with bromoarenes. ${ }^{109}$ Similar approach was employed by Singh et al. ${ }^{110}$ for immobilization of $\operatorname{Pd}(0)$ on silica gel. The prepared materials catalysed $\mathrm{C}-\mathrm{C}$ coupling reactions of substituted aryl bromides and iodides with acrylic acid or styrene in yields up to $92 \%$. The catalysts could be reused 15-16 times without any significant decrease in the yield of the coupling product. Their further reuse up to 30 times was also possible but the yield was reduced by $10-15 \%$.

A Pd(II)-SCS-pincer complex (A in Fig. 4) was covalently immobilised on mesoporous silica SBA-15 and evaluated as a precatalyst in Heck reaction. ${ }^{111}$ Kinetic experiments and poisoning studies indicated that the pincer complexes

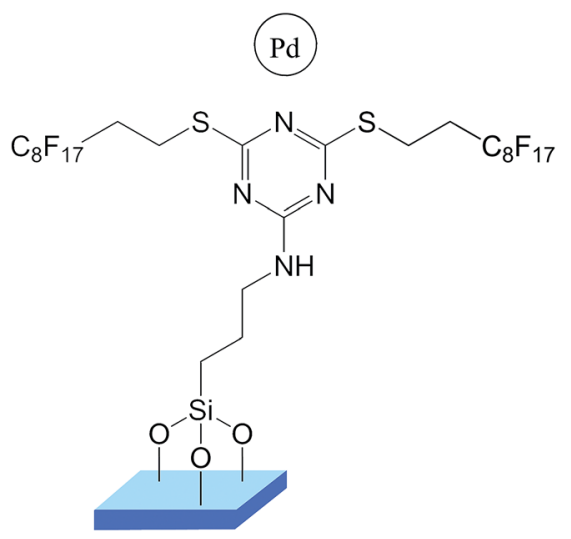

Fig. 3 Supported Pd-catalyst containing perfluoroalkyl ligand used in Heck coupling reaction. 
decompose under reaction conditions via rupture of the palladium-ligand bonds to liberate active $\operatorname{Pd}(0)$ species catalysing the reaction of iodobenzene with $n$-butyl acrylate. ${ }^{112}$ The same conclusion was made for the structurally related Pd/PCP-pincer complex (B in Fig. 4) grafted onto the same support. ${ }^{113}$

A saturated Pd-NHC complex was immobilised on amorphous silica by Artok and co-workers (Fig. 5). ${ }^{114}$ The complex itself was found thermally stable. However, TEM observations, hot filtration, reusability and poisoning tests revealed that the complex acted only as a precursor of active Pd species in the Heck reactions when immobilised. The complex appears more stable when used in homogeneous system (TON in the range $10^{4}$ to $10^{5}$ for the reaction of bromobenzenes with styrene to give trans-stilbenes). Karimi and Enders ${ }^{115}$ prepared a Pd-NHC complex on a silica support (via immobilised ionic liquids) and tested this material in the Heck reaction of aromatic halides with styrene and acrylic esters. Aryl iodides and bromides afforded good conversions (78-99\%), while chlorides did not react under the conditions used. The catalyst was recycled four times with only a minor loss of its activity.

\section{Suzuki-Miyaura reaction}

Suzuki-Miyaura reaction (Scheme 3) is a Pd-catalysed crosscoupling reaction between organic boron compounds (usually, boronic acids or boronic esters) and aryl or alkyl halides/ triflates proceeding under relatively mild reaction conditions. ${ }^{116}$ Similarly to the Heck coupling, this reaction is believed to proceed through the sequence of oxidative addition, transmetalation and reductive elimination, and requires a base for the activation of the boron component. Suzuki-Miyaura coupling represents a relatively simple, condition-tolerant and versatile $\mathrm{C}-\mathrm{C}$ bond forming reaction, which can be extended to various substrates and finds therefore wide applications in the synthesis of various simple and complex organic molecules, pharmaceuticals and natural products. ${ }^{117}$

Mubofu et al. prepared a highly active (TONs in the range of $10^{3}$ based on ten reuse experiments from batch reactions),

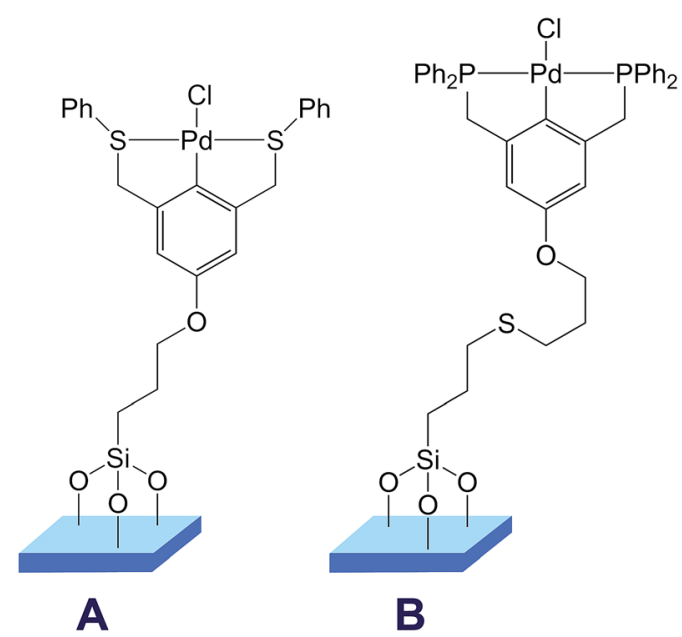

Fig. 4 Examples of pincer complexes used for Pd anchoring.

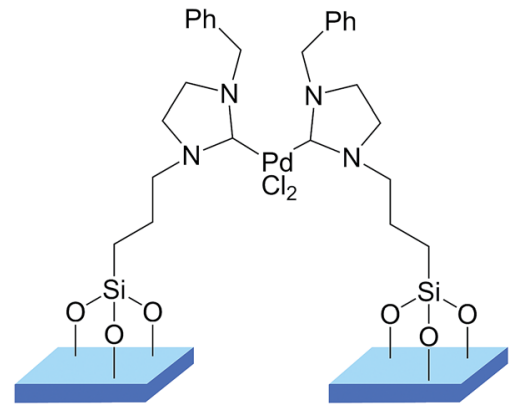

Fig. 5 Example of $\mathrm{Pd}-\mathrm{NHC}$ complex immobilised on silica for utilization in Heck reaction.

recyclable and robust supported palladium catalyst for Suzuki reaction between phenylboronic acid and bromobenzene. The catalysts were obtained by interaction of aminopropylated silica with pyridine carbaldehyde and subsequent complexation of palladium acetate. ${ }^{118}$

A series of silica supported palladium catalysts bearing $\mathrm{N}-\mathrm{N}$, $\mathrm{N}-\mathrm{S}$ and $\mathrm{N}-\mathrm{O}$ chelating ligands (Fig. 6) have been prepared by Clark et al. ${ }^{119,120}$ using three-step procedure consisting of modification of activated silica with (3-aminopropyl)trimethoxysilane, Schiff base condensation with 2-acetylpyridine (A), 2-pyridinecarbaldehyde (B), 2-thiophenecarbaldehyde (C), 2-furancarbaldehyde (D), 2-acetylfuran (E), 2-hydroxyacetophenone (F), 2-aminoacetophenone (G) or 2-pyrrolecarbaldehyde $(\mathrm{H})$ and, finally, metallation with palladium acetate. A clear but not linear relationship between the Pd binding energies from XPS measurements and the structure of the chelating ligands or rate constants in the Suzuki reaction between benzeneboronic acid and bromobenzene was found. The activity of prepared catalysts decreased with increasing binding energy in the following sequence: $\mathrm{A}<\mathrm{E}=\mathrm{F}<\mathrm{G}<\mathrm{C}<\mathrm{D}<$ $\mathrm{B}<\mathrm{H}$ (Fig. 6).

MCM-41-supported, possibly terdentate nitrogen ligand and its palladium(II) complex (Fig. 7) was synthesised and tested in Suzuki-Miyaura coupling between aryl bromides and arylboronic acids in ref. 121 Various electron-donating and electronwithdrawing groups such as $\mathrm{CH}_{3}, \mathrm{OCH}_{3}, \mathrm{Ph}, \mathrm{Cl}, \mathrm{CN}, \mathrm{NO}_{2}, \mathrm{CF}_{3}$, $\mathrm{COCH}_{3}$, and $\mathrm{CO}_{2} \mathrm{CH}_{3}$ in both aryl bromide and arylboronic acid components were found to be well tolerated and the reaction gave the desired substituted biaryls in good to excellent yields (up to 99\%). Even the reactions of bulky 1-naphthylboronic acid with aryl bromides proceeded satisfactorily, providing the coupling products in $81-85 \%$ yields. The catalyst was found to be reusable at least 10 times with a negligible loss in activity. The high stability and excellent reusability of the catalyst was

$$
\begin{array}{ll}
R-\mathrm{BX}_{2}+\mathrm{Y}-\mathrm{R}^{\prime} & \frac{\text { catalyst/base }}{-\mathrm{BX}_{2} \mathrm{Y}} \mathrm{R}-\mathrm{R}^{\prime} \\
\mathrm{R}=\mathrm{Ar} \text {, Alk, vinyl } & \mathrm{X}=\mathrm{H}, \mathrm{OH}, \text { OAlk } \\
\mathrm{R}^{\prime}=\mathrm{Ar} \text {, Alk } & \mathrm{Y}=\mathrm{Cl}, \mathrm{Br} \text {, I, OTf }
\end{array}
$$

Scheme 3 Suzuki-Miyaura reaction. 


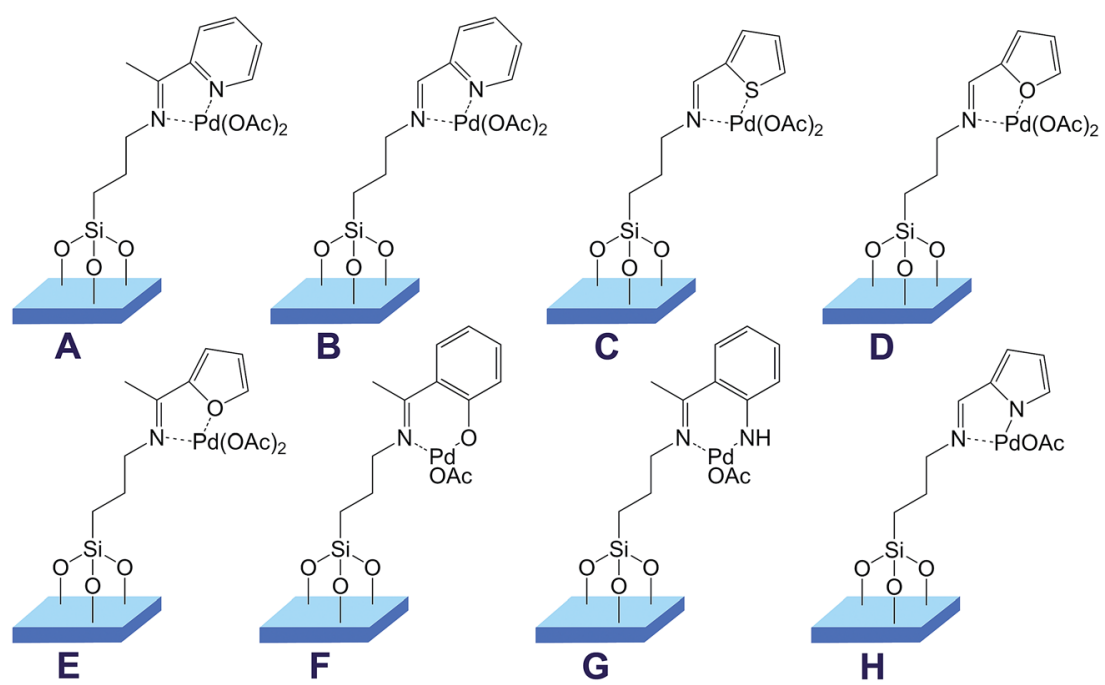

Fig. 6 The set of silica supported palladium catalysts bearing $\mathrm{N}-\mathrm{N}, \mathrm{N}-\mathrm{S}$ and $\mathrm{N}-\mathrm{O}$ chelating ligands used in Suzuki-Miyaura coupling.

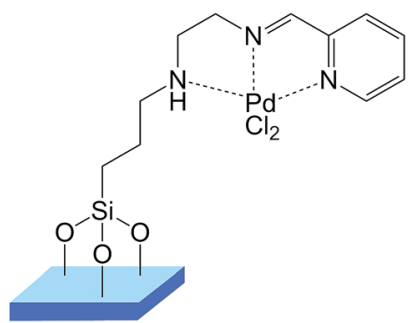

Fig. 7 MCM-41-supported complex of a terdentate nitrogen ligand and $\mathrm{Pd}(\Perp)$.

assumed to result from the chelating coordination of the NNNligand and metal binding properties of the mesoporous structure of MCM- 41 .

Silica supports modified with ligands of three different types (containing amino, diamino and pyridyl moieties) were used to prepare supported $\mathrm{Pd}(\mathrm{II})$ complexes for Suzuki coupling reactions by Vassylyev et al. ${ }^{122}$ The activity of the immobilised catalyst was found to be significantly higher in comparison with the respective molecular complexes, which was regarded as an evidence that heterogeneous and not homogeneous Pd contributed to the activity of the supported catalysts. Different catalyst required different base additives in order to achieve optimal results, which was explained by variation in the energy of transition complex formation upon changing the coordination sphere of Pd.

Another series of supported catalysts containing different amounts of palladium was prepared by treatment of SBA-15type mesoporous molecular sieve bearing the $\equiv \mathrm{Si}\left(\mathrm{CH}_{2}\right)_{3} \mathrm{NH}\left(\mathrm{CH}_{2}\right)_{2} \mathrm{NEt}_{2}$ groups at the surface with palladiu$\mathrm{m}(\mathrm{II})$ acetate. ${ }^{94}$ These catalysts were studied in Suzuki biaryl couplings to establish the influence of metal loading and "innocent" surface modifications (trimethylsilylation). It was found, that Suzuki reaction proceeds efficiently with both model and practically relevant substrates. The catalyst performance increased with an increasing degree of metalation (decreasing N/Pd ratio). Furthermore, catalyst poisoning tests revealed that the reaction takes place in the liquid phase with the catalyst serving as a reservoir of active metal species and also as a stabilizing support.

Pleixats and co-workers ${ }^{123}$ described the preparation of organic-inorganic hybrid mesostructured worm-like and hexagonally organised silica materials containing imidazolium and dihydroimidazolium salts from mono- and disilylated monomers, loaded these materials with Pd(II) and investigated the activity and recyclability of the resulting catalysts in SuzukiMiyaura cross-coupling. While all prepared materials showed efficient and fast reactions between the activated 4-bromoacetophenone and phenylboronic acid giving almost quantitative isolated yields of the target product in $0.5-1 \mathrm{~h}, \mathrm{Pd}(\mathrm{II})$ supported on worm-like hybrid support showed slightly better reusability than hexagonally ordered material, as no decrease in the activity was observed after five cycles and almost quantitative yields of the coupling product were isolated during these runs. Only $\operatorname{Pd}(\mathrm{II})$ catalysts supported on worm-like hybrids were tested as a recyclable catalyst for the Suzuki coupling of phenylboronic acid with the less reactive 4-chloroacetophenone. ${ }^{123}$ Although the yields were modest (34\%), the reusability of these catalysts was established with this rather challenging substrate. Highresolution transmission electron microscopy analysis of the $\operatorname{Pd}(\mathrm{II})$ catalyst supported on worm-like hybrids recovered after the 5th catalytic run revealed the formation of Pd nanoparticles (diameter $c a .3 \mathrm{~nm}$ ).

Gruber-Woelfler et al. ${ }^{124}$ applied a two-step procedure to prepare a Pd-catalyst from silica gel-tethered bis(oxazoline) (BOX) ligand. In particular, the covalent immobilization of $2,2^{\prime}-$ (1-methyl-11-dodecenylidene)bis(4,5-dihydrooxazole) on 3mercaptopropyl-functionalised silica gel, followed by metalation with $\mathrm{Pd}(\mathrm{OAc})_{2}$ provided a stable and active catalyst. The superior behaviour of the prepared catalyst in comparison with homogeneous $\left(\mathrm{BOX} / \mathrm{Pd}(\mathrm{OAc})_{2}\right)$ and in situ immobilised catalysts in Suzuki coupling reaction under various conditions was 
rationalised by self-deactivation of $\mathrm{Pd}(\mathrm{OAc})_{2}$ in liquid phase and by the poisoning effect of thiol groups in the in situ prepared catalyst. Using hot filtration test, three phase test, and ICP/OES analysis, the authors showed that there is virtually no Pd leaching into the reaction solution under the applied reaction conditions. Furthermore, the catalyst was found to be chemically stable and can be reused for at least 10 times.

Tyrrell and co-workers ${ }^{125}$ studied the activity of Pd-supported catalysts prepared via two complementary methodologies (i.e., by complexation of grafted imidazolium moieties and by immobilization of defined complexes). A comparison of catalyst prepared by immobilization of the imidazolium salt to silica before the formation of the NHC complex (route A, Scheme 4), and catalyst resulting via grafting the NHC complex directly onto silica (route B, Scheme 4), revealed that the former one provides an $84 \%$ yield of the coupling product at the $0.2 \mathrm{~mol} \%$ metal loading, while second one gave a $90 \%$ yield under the same conditions. These data suggest that the catalysts prepared by immobilizing the pre-formed palladium complexes is slightly more active in the Suzuki coupling of aryl bromides than that prepared by the reaction of palladium acetate with the tethered imidazolium salt. Furthermore, the use of sterically bulky NHCs (such as the 2,6-(diisopropyl)phenyl-substituted ligand) resulted in an increased catalytic activity (conversions of $>99 \%$ under the same reaction conditions), suggesting that bulkiness of the ligand plays an important role in controlling the catalytic activity of tethered palladium NHC catalysts.

Gude and Narayanan investigated the catalytic activity for three types of nanocatalysts - colloidal supported metal nanoparticles (CSMNs) prepared with silica colloids in solution, ${ }^{126}$ CSMNs prepared from dry silica colloids re-suspended in doubly deionised water, and palladium nanoparticles loaded onto bulk silica dispersed in doubly deionised water - in the Suzuki-Miyaura reaction between phenylboronic acid and iodobenzene. These three types of catalysts were prepared with and without the addition of APTES. The CSMNs obtained from non-functionalised wet silica colloids and palladium nanoparticles surprisingly showed the highest catalytic activity as compared to their counterparts prepared using the APTES linker. The authors assumed that APTES could act as a catalyst poison resulting in a lower catalytic activity in the Suzuki reaction. ${ }^{126}$

In an attempt to clarify the effectiveness of a tripodal linker unit (e.g. 3-bromopropyltris[3-(dimethylisopropoxysilyl)propyl]silane), which can be bound to a silica surface via three independent $\mathrm{Si}-\mathrm{O}-\mathrm{Si}$ bonds, silica-immobilised palladium amine complex catalysts employing this linker unit were prepared and applied in the Suzuki coupling reaction of 4-bromobenzoic acid ethyl ester and phenylboronic acid. ${ }^{127} \mathrm{Pd}$ (II) supported on functionalised silica containing 3-(methylamino)propyl moiety, which comprises a secondary amine ligand, gave a higher yield than Pd(II) grafted on support bearing tertiary amine modifying group (i.e. 3-(dimethylamino)propyl). $\mathrm{Pd}(\mathrm{II})$ catalyst resulting from the chelating ligandcontaining support exhibited a low catalytic activity. However, the hot filtration test suggested a substantial contribution from homogeneous catalytic reaction due to leached-out palladium species for the most active catalyst based on 3-(methylamino) propyl ligand. Thus, the authors concluded, that the order of activity among the catalysts with different amino ligands just reflects the degree of palladium dissociation from the palladium complexes immobilised on the silica support. ${ }^{127}$

Rossi et al. ${ }^{128}$ reported the preparation of supported palladium nanoparticles stabilised by pendant phosphine groups by reacting a palladium complex $\left[\mathrm{Pd}(\mathrm{OAc})_{2} \mathrm{~L}_{2}\right]$, where $\mathrm{L}$ is 2(diphenylphosphino)benzaldehyde, with an aminopropylfunctionalised silica. The material proved to be an active catalyst in the Suzuki-Miyaura cross-coupling. Catalyst deactivation caused by silica etching and Pd nanoparticles aggregation was observed in the successive runs and demonstrated to be partly minimised upon following an alternative protocol consisting of addition of the base to the arylboronic acid solution prior to the contact with the catalyst. This approach allowed for catalyst reuse for up to ten recycles, while keeping similar catalytic activity during seven successive reactions.

A Pd(II) catalyst derived from MCM-41 functionalised with NNN-donor groups has been synthesised by Dhara et al. ${ }^{129}$ by anchoring of APTS in the MCM-41 mesoporous molecular sieve, followed by reaction with 2,6-diacetylpyridine to give a N3-type Schiff base and metalation with Pd salt. The prepared material behaved as a highly active catalyst for the Suzuki-Miyaura cross-coupling reaction of both electron-poor (yields $92-98 \%$ after $3 \mathrm{~h}$ TOS, TOF $>4400 \mathrm{~h}^{-1}$ ) and electron-rich (yields 90-95\% after 4-8 $\mathrm{h}$ TOS, TOF $>2200 \mathrm{~h}^{-1}$ ) aryl halides with phenylboronic acid. Hot filtration and three phase test excluded any significant leaching of Pd species. ${ }^{129}$

The organosilane-based NHC-Pd complex immobilised covalently on silica was shown to be efficient reusable heterogeneous catalyst in the Suzuki reaction of various aryl halide

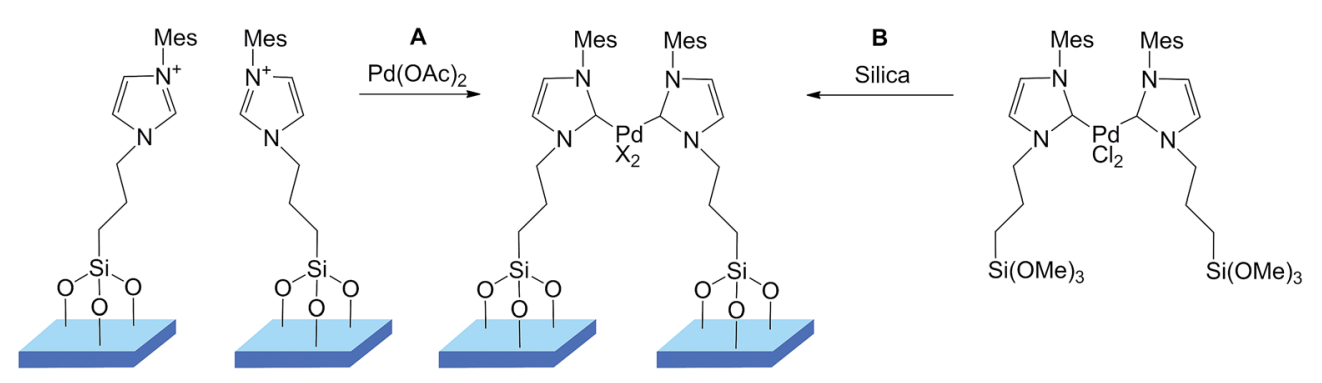

Scheme $4 \mathrm{Pd}$-supported catalyst prepared via complexation of grafted imidazolium moieties (A) and immobilization of defined complex (B). 
derivatives (except for aryl chloride derivatives) with phenylboronic acid under mild conditions. ${ }^{\mathbf{1 3 0}}$

Crudden et al. ${ }^{\mathbf{1 0 0}}$ demonstrated a high catalytic activity of Pd immobilised on mercaptopropyl-modified SBA-15 in SuzukiMiyaura reactions of bromo- and chloroaromatics. Heteroaromatic substrates such as 3-bromopyridine and deactivated substrates such as 4-bromoanisole also underwent coupling reaction with good to excellent yields (82-99\%). Reproducible high catalytic activity was observed in DMF, water or a mixture of the two solvents. In contrast to Pd immobilised on mercaptopropyl-modified silica, these materials could be reused several times with virtually no loss of activity, even in water. Later, it was shown that the method of introducing the alkylthiol groups influences the stability of such Pd-supported catalysts. $^{\mathbf{1 3 1}}$ A grafting approach gave a significantly more stable material, likely owing to protection of the siliceous surface from attack by the aqueous base, while the incorporation of the thiol by co-condensation provided a material with a minimal stability under the reaction conditions. Mesostructured mercaptopropyl-modified SBA-16 and KIT-6 materials were also shown to be viable solid supports for the immobilization of $\mathrm{Pd}(0)$ and $\mathrm{Pd}(\mathrm{II})$ complexes. ${ }^{132}$ The behaviour of the last ones in the Suzuki-Miyaura coupling reaction of 4-bromoacetophenone and phenylboronic acid pinacol ester was comparable to that of Pd immobilised on mercaptopropyl-modified SBA-15.

Sullivan and co-workers ${ }^{\mathbf{1 3 3}}$ reported on $\mathrm{Pd}(\mathrm{II})$ complexes immobilised on porous silica ( $6 \mathrm{~nm}$ pore size) modified by disulfides $(\mathrm{MeO})_{3} \mathrm{Si}\left(\mathrm{CH}_{2}\right)_{2} \mathrm{~S}\left(\mathrm{CH}_{2}\right)_{n} \mathrm{~S}\left(\mathrm{CH}_{2}\right)_{2} \mathrm{Si}(\mathrm{OMe})_{3}(n=2,3)$, that showed high activity, reusability and resistance in the Suzuki-Miyaura reaction of aryl bromides with arylboronic acids at room temperature in isopropanol. The same authors ${ }^{\mathbf{1 3 4}}$ used co-condensation of TEOS with methyl[3-(triethoxysilyl)ethyl]thioglycolate to prepare $\equiv \mathrm{SiCH}_{2} \mathrm{CH}_{2} \mathrm{SCH}_{2} \mathrm{CO}_{2} \mathrm{Me}$ modified silica. Subsequent hydrolysis of the anchored ester group and reaction with palladium(II) acetate afforded a stable and recyclable supported $\mathrm{Pd}$-catalyst (presumably with $O, S$-chelated Pd centres), which was successfully tested in Suzuki-Miyaura cross-coupling of aryl bromides with phenylboronic acid. $\mathbf{. 3 4}^{\mathbf{3 4}}$

SBA-15 mesoporous support silylated at the outer surface with $\mathrm{PhSi}(\mathrm{OMe})_{3}$ (prior to removal of the template) was functionalised with $\mathrm{Ph}_{2} \mathrm{PC}_{6} \mathrm{H}_{4} \mathrm{CH}_{2} \mathrm{~S}\left(\mathrm{CH}_{2}\right)_{3} \mathrm{Si}(\mathrm{OEt})_{3}$ and then metalated with $\left[\mathrm{Pd}_{2}(\text { dibenzylideneacetone })_{3}\right]$ to afford an immobilised Pd-“triphenylphosphine" catalyst (Fig. 8). This recyclable catalyst was employed in Suzuki-Miyaura reaction of aryl bromides with arylboronic acids carried out in supercritical carbon dioxide, from which the reaction products separated upon cooling (isolated yields of biphenyls were in the range 83$99 \%) .^{135}$

MCM-41-supported bidentate phosphine $\operatorname{Pd}(0)$ complex synthesised by treatment of MCM-41 with APTES and then with (diphenylphosphino)methanol and palladium chloride and subsequent reduction with hydrazine hydrate mentioned above was shown to efficiently catalyse Suzuki-Miyaura reaction of aryl iodides and bromides with arylboronic acids (yields 84$98 \%$ ). The negative hot filtration test was regarded by authors as an evidence of true heterogeneous nature of this catalyst. ${ }^{\mathbf{1 3 6 , 1 3 7}}$ Suzuki-Miyaura cross-coupling reactions of various aryl

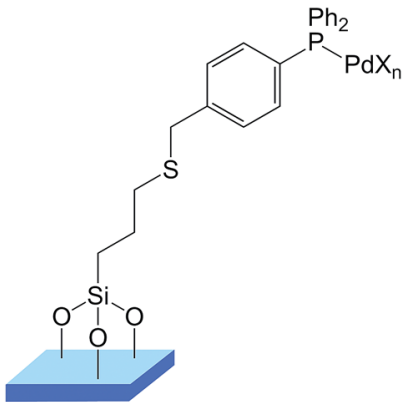

Fig. 8 Immobilised $\mathrm{Pd}$-phosphine complex utilised in SuzukiMiyaura reaction.

chlorides with arylboronic acids were examined also under different reaction conditions over $\operatorname{Pd}(0)$ immobilised on mesoporous-supported aryldicyclohexylphosphine, synthesised using a four-step approach (Scheme 5). ${ }^{\mathbf{1 3 8}}$ High conversions and yields (81-98\%) were achieved for activated aryl chlorides.

Corma et al. ${ }^{139}$ attempted to develop another heterogeneous Pd-supported catalyst by anchoring 2-dicyclohexylphosphino$2^{\prime}, 6^{\prime}$-dimethoxy-1,1'-biphenyl (S-Phos) ligand on different solid supports such as non-soluble (cross-linked polystyrene) and soluble (non-cross-linked polystyrene and polyethyleneglycol) polymers, as well as high surface silica. The immobilised ligand was in situ converted to a palladium-phosphine complex. While the complete conversions and high selectivity to the expected trimethylbiphenyl was observed in Suzuki reaction of 2-chloro$m$-xylene and 2-tolylboronic acid for the two SPhos ligands anchored on soluble supports, SPhos anchored on silica proved to be completely inactive in this coupling reaction.

Jin et $a l .{ }^{\mathbf{1 4 0}}$ reported the synthesis of hierarchical micromesoporous LTA zeolite-supported $\beta$-oxoiminatophosphinopalladium complex (Scheme 6) and its application as a catalyst for Suzuki-Miyaura reaction of aryl and heteroaryl chlorides. The catalyst achieved typically 80-90\% conversions with 1 $\mathrm{mol} \% \mathrm{Pd}$ in aqueous ethanol in $5 \mathrm{~h}$.

\section{Sonogashira reaction}

The Sonogashira reaction (Scheme 7) is a palladium-catalyzed $\mathrm{sp}^{2}$-sp cross-coupling reaction between a terminal alkyne and an aryl or vinyl halide/triflate performed with or without the presence of a copper(I) co-catalyst. ${ }^{141}$ It has become one of the most important methods to prepare arylalkynes and conjugated enynes, which represent reactive intermediates en route to many natural products and pharmaceuticals. ${ }^{142-146}$

Palladium immobilised on silica modified with $\equiv \mathrm{Si}\left(\mathrm{CH}_{2}\right)_{3}$ $\mathrm{NHCH}_{2} \mathrm{CH}_{2} \mathrm{NH}_{2}$ pendant groups was studied in the Sonogashira reaction of terminal alkynes with aromatic iodides. Reactions performed at $1 \mathrm{~mol} \%$ Pd loading in refluxing ethanol with potassium carbonate as the base generally provided good yields of the coupling products ( $>90 \%)$. Reactions with aryl bromides typically required a higher temperature $\left(110{ }^{\circ} \mathrm{C}\right.$ in DMF) to achieve similar conversions. The catalyst proved to 


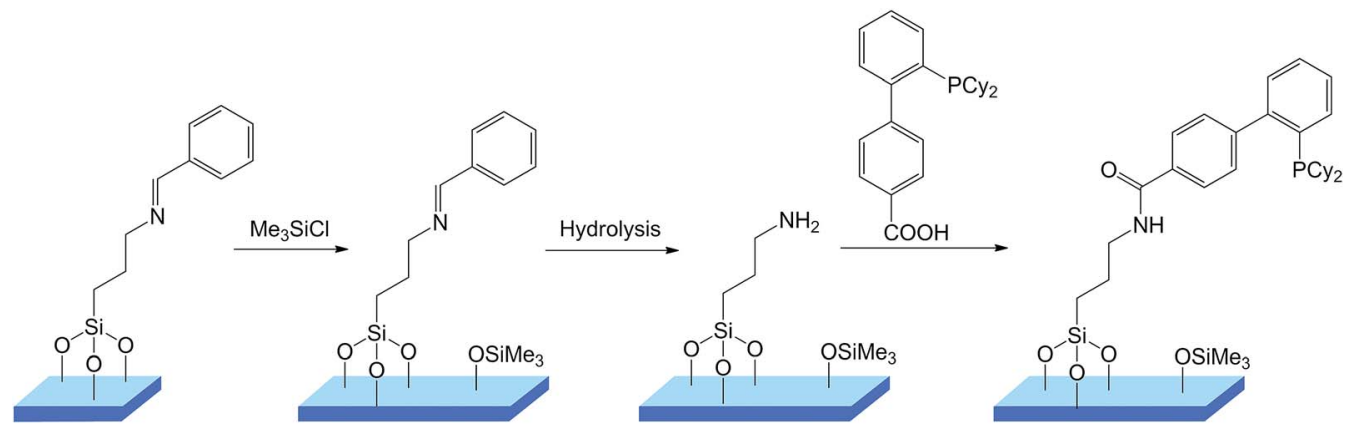

Scheme 5 Immobilization of a (dicyclohexyl)biphenyl moiety (Cy = cyclohexyl).

have excellent stability, being used during as much as 30 consecutive runs without any decrease in the activity. ${ }^{\mathbf{1 4 7}}$

Asefa and co-workers ${ }^{\mathbf{1 4 8}}$ reported the synthesis of bifunctional mesoporous catalysts by immobilization of two functional moieties, a $\mathrm{Pd}(\mathrm{II})$-diamine complex and a primary amine group $\left(-\mathrm{NH}_{2}\right)$, onto mesoporous MCM-41 and SBA-15 silicas, and demonstrated their use as heterogeneous catalysts for onepot two-step sequential Sonogashira and Henry reactions (Scheme 8). The bifunctional, SBA-15-based catalyst afforded $60 \%$ yield for the Sonogashira-Henry tandem product in $5 \mathrm{~h}$. The bifunctional catalyst also catalyzed both reactions, individually resulting in approximately $100 \%$ reactant conversion in $2.5 \mathrm{~h}$ in the Sonogashira reaction and approximately $100 \%$ reactant conversion in $45 \mathrm{~min}$ in the Henry reaction.

Sugi et al. investigated the catalytic activity of an quinoline-2carboimine palladium complex immobilised on MCM-41 (Fig. 9) in Sonogashira reaction of various terminal and aliphatic alkynes with aryl and halides. ${ }^{149}$ The catalyst provided excellent yields ( $>93 \%$ in most of the cases) of the corresponding cross-coupling products in reactions of terminal alkynes containing aryl substituents. On the other hand, only moderate catalytic activity was observed in reactions of an aliphatic alkyne due to a lower acidity of its terminal proton. The supported Pd catalyst was reusable without significant loss of catalytic activity until the fourth recycle under aerobic conditions. Its catalytic performance was ascribed to effective catalysis by the quinoline2-carboimine palladium complex immobilised on MCM-41 support with high BET area and to a high air-stability of the catalyst.

Analogous Pd catalysts obtained from imine-modified supports resulting by reactions of conventional aminopropylated silica with 2-pyridinecarbaldehyde, 2-acetylpyridine,

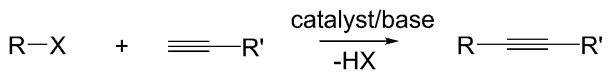

$$
\begin{aligned}
& \mathrm{R}=\mathrm{Ar} \text {, vinyl } \\
& \mathrm{R}^{\prime}=\mathrm{Ar}, \text { Alk, vinyl, CoOAlk } \\
& \mathrm{X}=\mathrm{Cl}, \mathrm{Br} \text {, I, OTf }
\end{aligned}
$$

Scheme 7 Sonogashira coupling.

or 2-(diphenylphosphino)benzaldehyde were efficient catalysts for Sonogashira reaction of ethynylbenzene (phenylacetylene) with different aryl iodides affording the respective substituted tolanes. ${ }^{76}$ Possible beneficiary effect of the phosphine donor groups arising from 2-(diphenylphosphino)benzaldehyde was partly eliminated by their oxidation to the corresponding phosphine oxide occurring during the catalyst preparation as evidenced by solid-state ${ }^{31} \mathrm{P}$ NMR measurements.

Trilla and co-workers ${ }^{\mathbf{1 5 0}}$ firstly synthesised hybrid silica materials with anchored di(2-pyridyl)methylamine-dichloropalladium(II) (Fig. 10). These catalysts were prepared by sol-gel co-gelification and found to behave as efficient and recyclable catalysts for the Sonogashira reaction of phenylacetylene and aryl bromides or iodides. ${ }^{\mathbf{1 5 0}}$ Notably, no Pd nanoparticles were formed during the course of the Sonogashira coupling over this catalyst. However, hot filtration test evidenced that both homogeneous and heterogeneous pathways participate in the catalytic process.

Hankari et al. investigated the influence of the structure of the thiol precursor on the morphology of the mesoporous silica resulting by template-directed condensation or by postsynthetic grafting. ${ }^{151}$ Catalytic properties of the resulting Pdimpregnated materials were compared with the "classical"

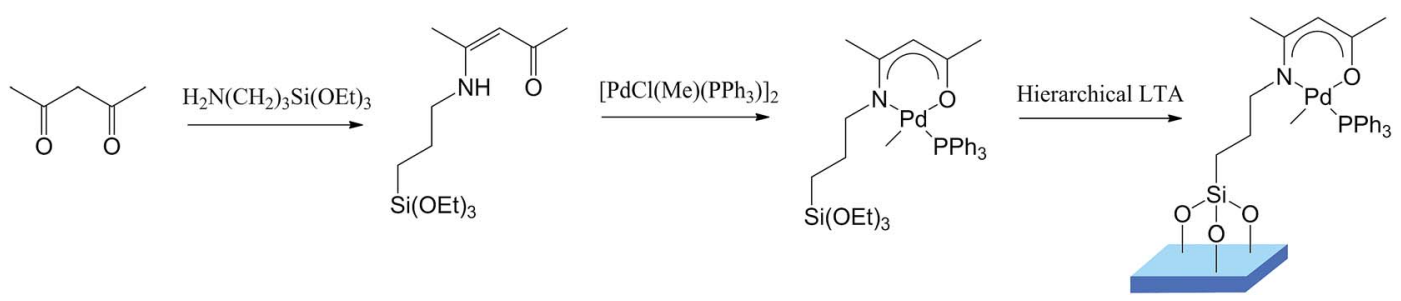

Scheme 6 Synthesis of zeolite-supported $\beta$-oxoiminatophosphinopalladium complex. 


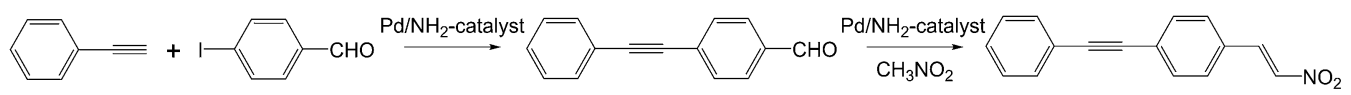

Scheme 8 Sonogashira-Henry tandem reaction.

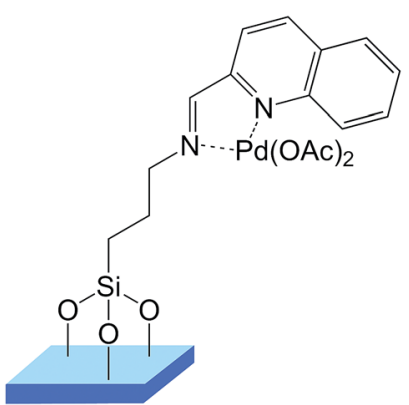

Fig. 9 Quinoline-2-carboimine palladium complex immobilised on silica support.

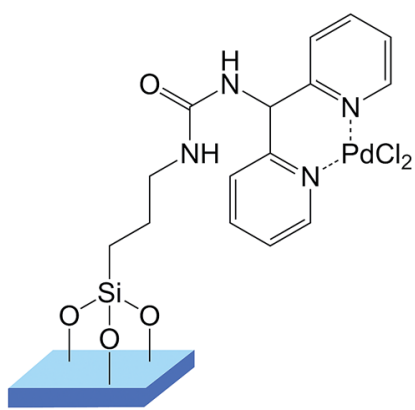

Fig. 10 Bis(2-pyridyl)methane-Pd complex immobilised via an urea spacer.

mercaptopropyl-functionalised silica obtained from (3-mercaptopropyl)triethoxysilane by direct hydrolysis/cocondensation with TEOS and subsequent impregnation with a Pd(II) salt. Compared with conventional thiol-functionalised materials obtained from mercaptopropyl-trialkoxysilane precursors, the new reported thiol-functionalised silica materials showed significantly improved recyclability. This result was attributed to a higher hydrophobicity of these materials, imparted by the bulkier bis-silylated amide-thiol precursor. ${ }^{151}$

\section{Carbonylation/carboxylation}

Oxidative carbonylation of phenol with carbon monoxide and oxygen (Scheme 9) is considered as one of the most practically relevant methods for the preparation of diphenyl carbonate from cheap and simple feedstock reagents. ${ }^{122,153}$ Using the solgel technique, Li et al. prepared Pd complexes anchored on silica previously functionalised by silylpropropylated 1,2-diaminocyclohexane and tested these materials as catalysts in this reaction. ${ }^{154}$ The highest yield of diphenyl carbonate (12\%) was obtained with $\mathrm{Cu}_{2} \mathrm{O}$ as a co-catalyst while THF was the optimum solvent in terms of the yield and selectivity to diphenyl

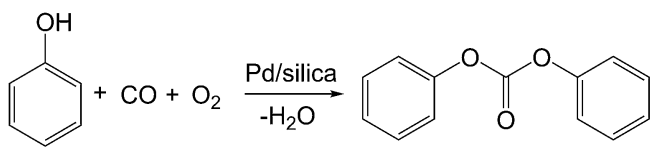

Scheme 9 Oxidative carbonylation of phenol

carbonate as well as low palladium leaching. Under the optimal conditions, the TON reached $60 \mathrm{~mol}$ of diphenyl carbonate $/ \mathrm{mol}$ Pd and the metal leaching did not exceed 3\%. The heterogeneous catalysts revealed higher catalytic activity compared with the homogeneous counterparts $\left(\mathrm{Pd}(\mathrm{OAc})_{2}\right.$ and $\left.\mathrm{PdCl}_{2}\right)$. It was also found, that the Pd loading significantly affects the reaction rate and the optimum Pd loading was found at $c a .5 \mathrm{wt} \%$. The intermediacy of $\operatorname{Pd}(0)$ in the catalytic cycle was verified, while the recovered catalyst was found to contain a mixture of $\mathrm{Pd}(\mathrm{II})$ and $\operatorname{Pd}(0)$ species.

Chaudhari et al. ${ }^{155}$ immobilised Pd and Pt nanoparticles on 3-aminopropylated zeolite NaY. In the presence of iodide promoters, the obtained materials exhibited high catalytic activities in oxidative carbonylation of aliphatic and aromatic amines to give symmetrically disubstituted ureas (Scheme 10; conversions in the range of $69-98 \%$, selectivities $>90 \%$ ). It was reported, that the immobilised Pd nanocatalyst exerts a higher activity (TOF of $157 \mathrm{~h}^{-1}$ ) than the previously reported materials, which is maintained even at relatively lower temperatures and pressure. $^{156-158}$

Palladium species immobilised inside functionally modified mesoporous materials (MCM-41, MCM-48, SBA-15) have been also synthesised by Chaudhari et al. ${ }^{159}$ The starting material containing 3-aminopropyl functional groups were prepared via different synthesis strategies (viz. post-synthesis grafting and one-pot co-condensation). Characterization (in particular by ${ }^{13} \mathrm{C},{ }^{29} \mathrm{Si}$ and ${ }^{31} \mathrm{P}$ solid-state CP-MAS NMR spectroscopy) confirmed that the anchoring of the complex $[\operatorname{Pd}($ pyridine-2carboxylate) $\left.\left(\mathrm{PPh}_{3}\right)(\mathrm{OTs})\right]$ occurred as anticipated. The materials showed high activity (TOF $350-750 \mathrm{~h}^{-1}$ ), chemo- and regioselectivity of $>99 \%$, stability and recyclability in low-pressure carbonylation of olefins and alcohols to carboxylic acids (Scheme 11), with the catalyst based on SBA-15 synthesised by post-synthetic grafting approach showing the highest activity.

Lagasi and Moggi prepared triethoxysilyl-substituted amines by Schiff condensation of APTES with 2-acetylpyridine, 2,6-

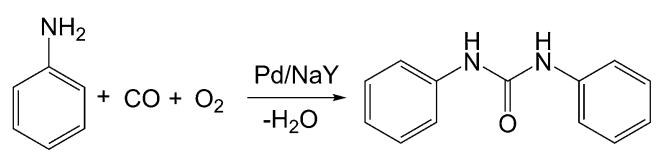

Scheme 10 Oxidative carbonylation of aniline to the corresponding $\mathrm{N}, \mathrm{N}$-disubstituted urea. 


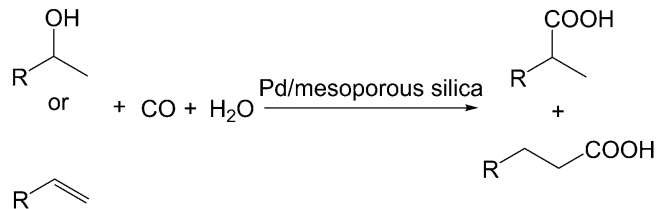

Scheme 11 Carbonylation of olefins and alcohols to carboxylic acids.

diacetylpyridine, or 2-acetylpyrazine and subsequent reduction using $\mathrm{Na}\left[\mathrm{BH}_{4}\right]$. The amines were employed in co-condensation with TEOS to afford functionalised silicas. ${ }^{160}$ Materials obtained after treatment with a Pd salt were probed as reusable catalysts for methoxycarbonylation of iodobenzene (Scheme 12). Catalyst prepared from 2-acetylpyridine reached TON of 2300 after 20 cycles in the presence of triethylamine as a base promoter and also showed the highest stability during recycling tests: $83 \%$ conversion of iodobenzene and $97 \%$ selectivity to methyl benzoate was achieved after 20th run without deactivation through leaching of palladium.

Double carbonylation of aryl iodide derivatives with secondary and primary amines to produce $\alpha$-ketoamides (Scheme 13) over a series of silica supported palladium complexes with varying electronic properties and steric hindrance was described by Genelot et al. ${ }^{161}$ Conversions up to $80 \%$ and selectivities up to $96 \%$ for the double carbonylated $\alpha$ ketoamide products (the other product being the respective amide) were achieved in reactions of different aryl iodides with secondary and primary amines. It was demonstrated that two palladium complexes (designed with monodentate phosphine or chelating diphosphine linkers) supported on mesoporous SBA-15 material can be used repeatedly without a notable loss of activity and selectivity.

$\mathrm{Lu}$ and Alper ${ }^{162}$ reported the synthesis of various dendrimers immobilised on silica support via Michael-type addition and amidation reactions, followed by the phosphinylation with (diphenylphosphino)methanol. The resulting phosphineterminated dendrimers were then reacted with a palladium salt to give the dendrimer Pd-complexes, and the resulting materials were tested in the synthesis of oxygen, nitrogen, or sulfur-containing medium ring fused heterocycles by intramolecular carbonylation reactions (Scheme 14). The dendritic catalysts exhibited very good activities in these transformations, affording the desired heterocycles in high yields $(>90 \%$ in most of the cases). Importantly, a wide variety of functional substituents were tolerated in this process, including chloro, methoxy, trifluoromethyl, cyano, acetyl, and methoxycarbonyl groups, and the catalysts could be used in eight successive cycles with

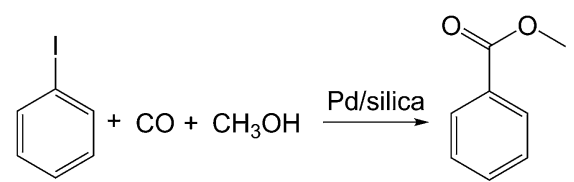

Scheme 12 Methoxycarbonylation of iodobenzene to methyl benzoate.

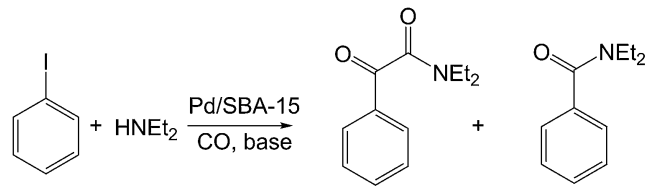

Scheme 13 Carbonylation of aryl iodide with secondary amine.

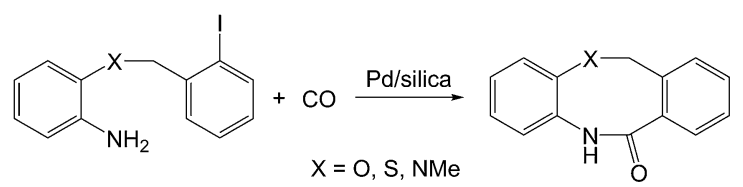

Scheme 14 Synthesis of $\mathrm{O}-, \mathrm{N}-$, S-containing heterocycles by intramolecular carbonylation reactions.

only a slight decrease of their activity (total decrease in the yield was only $5 \%$ ).

Carbonylative cross-coupling reactions, namely the synthesis of substituted ketones by reaction of arylboronic acids ${ }^{163}$ or terminal alkynes ${ }^{164}$ with aryl iodides under an atmospheric pressure of carbon monoxide (Scheme 15), have been studied by Cai and co-workers. In the first case, 3-(2-aminoethylamino) propyl-functionalised MCM-41-immobilised palladium(II) catalyst was applied, while a MCM-41-supported bidentate phosphine palladium(0) complex was used for the carbonylative Sonogashira coupling reaction. These heterogeneous catalysts proved useful in the synthesis of diaryl and aryl-alkynyl ketones as they exhibited higher activity and selectivity than homogeneous catalyst $\left[\mathrm{PdCl}_{2}\left(\mathrm{PPh}_{3}\right)_{2}\right]$, and showed only negligible decrease in the activity after several catalytic cycles (cf. $91 v s$. $89 \%$ yield and 45.5 vs. 44.5 TON in the 1st and 10th run, respectively, in the reaction of arylboronic acids with aryl iodides).

\section{Oxidation of alcohols}

Selective oxidation of alcohols represents an attractive method of the production of aldehyde or ketone intermediates for fine chemistry. In particular, aromatic and allylic oxo compounds can be synthesised with high selectivity through selective oxidation of the corresponding alcohols and used as

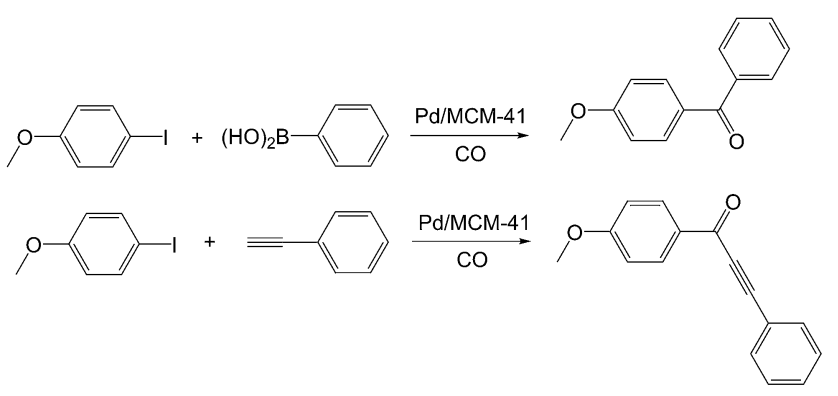

Scheme 15 Synthesis of substituted ketones by carbonylative reactions of arylboronic acids (top) or terminal alkynes (bottom) and aryl iodides. 
components of pesticides, perfumes or flavours. ${ }^{165,166}$ However, such reactions traditionally utilise toxic and hazardous stoichiometric reagents and generate large quantities of contaminated waste. ${ }^{167,168}$ During a search for alternative catalytic routes, Pd-supported heterogeneous catalysts emerged as attractive surrogates facilitating selective transformation of alcohols to aldehydes or ketones under moderate conditions via oxidative dehydrogenation mechanism. ${ }^{169}$

Recently, Lee et al. ${ }^{\mathbf{1 7 0}}$ reported about grafting of ultrathin alumina monolayers onto SBA-15 silica framework followed by impregnation of the resulting Al-SBA-15 with palladium. The formed Pd nanoparticles showed a good dispersion and surface oxidation characteristic of pristine aluminas with high active site densities typical for thermally stable, high-area mesoporous silicas. This combination allowed for significant rate enhancements in the aerobic selective oxidation of cinnamyl alcohol to cinnamic aldehyde (Scheme 16) over Pd/Al-SBA-15 as compared with Pd on mesoporous alumina or silica supports investigated by the same group earlier. ${ }^{171,172}$ Although Pd/Al-SBA-15 afforded a higher reaction rate in this selective oxidation than a $\mathrm{Pd} / \mathrm{meso}$ $\mathrm{Al}_{2} \mathrm{O}_{3}$ catalyst, their corresponding TOFs per surface active sites were almost identical suggesting the involvement of similar active species and palladium-support interaction. It was proposed that the higher activity and TOFs observed for alumina $\left(13500 \mathrm{~h}^{-1}\right)$ than silica $\left(6100 \mathrm{~h}^{-1}\right)$ supported palladium catalyst reflect a superior ability of the former material to disperse and preserve smaller PdO nanoparticles during the oxidation. In addition, operando XAS measurements revealed strong correlations between the palladium oxidation state and its activity, which identify rapid on-stream PdO reduction as the major deactivation pathway that can be partly eliminated by an increase of the oxygen pressure.

Wilson et al. ${ }^{\mathbf{1 7 2}}$ reported similar materials employing amorphous silica as well as SBA-15, SBA-16 and KIT-6 molecular sieves as supports for the Pd particles. The catalysts were tested in selective oxidation of crotyl alcohol and cinnamyl alcohol. The relative activities for both alcohols were dependent on the degree of mesopore connectivity and palladium dispersion/ oxidation state, which corresponds with the previous studies demonstrating the benefits of interconnected pore architectures. $^{173}$

Three-dimensional interconnected KIT- 6 and SBA-16 conferred the highest initial reaction rates $\left(24000 \mathrm{mmol} \mathrm{g}^{-1} \mathrm{~h}^{-1}\right)$, that proved to be superior to the two-dimensional SBA-15 (14 000 mmol $\mathrm{g}^{-1} \mathrm{~h}^{-1}$ ), which in turn outperformed commercial amorphous silica (6000 mmol g ${ }^{-1} \mathrm{~h}^{-1}$ ). Rate enhancements observed with interconnected mesoporous supports were also explained by their ability to stabilise dispersed palladium nanoparticles (1-2 $\mathrm{nm}$ ) and thus provide a material with a high palladium oxide surface. Rate analysis and controlled experiments using in situ

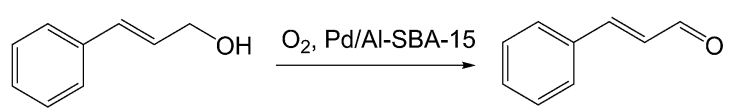

Scheme 16 Aerobic selective oxidation of cinnamyl alcohol to cinnamic aldehyde. reduction/oxidation conditions confirmed surface palladium oxide as the active species in selective oxidation of allyl alcohol. On the other hand, slow reduction of palladium nanoparticles under oxygen-limited reaction conditions was shown to reduce the reaction rates and favour undesired hydrogenolysis of cinnamyl alcohol to trans- $\beta$-methylstyrene.

Yang et al. ${ }^{\mathbf{1 7 4}}$ used mesoporous molecular sieve SBA-16 modified with (3-aminopropyl)triethoxysilane and hexamethydisilazane to prepare deposited Pd and Pd/Au catalysts, which were tested in solvent-free oxidation of benzyl alcohol to benzaldehyde with molecular oxygen. It was found that aminefunctionalization remarkably improves the selectivity towards the desired product. $\mathrm{Au} / \mathrm{Pd}$ bimetallic catalysts showed better catalytic performance than the respective monometallic catalysts ( $\mathrm{Au}$ and Pd). The highest turnover frequency (about $8700 \mathrm{~h}^{-1}$ ) was achieved over a bimetallic catalyst with $\mathrm{Au}$ : Pd molar ratio equal to $1: 5$. A similar catalyst has been tested in aqueous phase. ${ }^{175}$ In oxidation of different benzylic (Scheme 17) and allylic alcohols in the absence of a base performed under air or in $\mathrm{O}_{2}$ atmosphere in water, the prepared bimetallic catalysts exhibited conversions up to $99 \%$. The selectivities to the corresponding aldehydes and ketones were better than $99 \%$ in all the cases. Importantly, the catalyst could be recovered and reused twelve times without significant changes in the reaction outcome (conversion and selectivity).

Other $\mathrm{Au} / \mathrm{Pd}$ bimetallic catalysts supported on layered double hydroxide have been prepared and characterised by Hou et al. ${ }^{176}$ These bimetallic catalysts showed much higher activity than the corresponding monometallic catalysts in selective alcohol oxidation (Scheme 18) in water. Authors suggested that synergetic interaction between $\mathrm{Au}$ and $\mathrm{Pd}$ is responsible for the high efficiency of these $\mathrm{Au} / \mathrm{Pd}$ catalysts. The leaching test and elemental analysis showed that only a small amount of Pd (0.7 $\mathrm{ppm}$ ) and $\mathrm{Au}$ (traces) were leached out from the catalysts during the reaction.

$\mathrm{Li}$ and co-workers ${ }^{\mathbf{1 7 7}}$ utilised mesoporous silica nanoparticles as a support for the preparation of deposited bimetallic $\mathrm{Pd}-\mathrm{Au}$ catalyst by the conventional impregnationhydrogen reduction method. The resultant materials were evaluated in base-free oxidation of benzyl alcohol with oxygen (see Scheme 17 above). It was found that addition of a small amount of Pd (the Pd/Au atomic ratio was as low as 0.05/1) significantly decreases the size of the gold particles and thereby remarkably enhance the catalyst activity. At the optimal $\mathrm{Pd} / \mathrm{Au}$ atomic ratio of $0.2 / 1$, the respective bimetallic catalyst showed 8-times and 3-times higher activity than the respective monometallic Au- and Pd-containing catalysts.

Yang et al. ${ }^{178}$ prepared a series of supported $\operatorname{Pd}(0)$ catalysts by surface modification of mesoporous molecular sieve TUD-1 with APTES, (EtO) $)_{3} \mathrm{Si}\left(\mathrm{CH}_{2}\right)_{3} \mathrm{NHCH}_{2} \mathrm{CH}_{2} \mathrm{NH}_{2}$, (EtO) $)_{3} \mathrm{Si}\left(\mathrm{CH}_{2}\right)_{3} \mathrm{SH}$

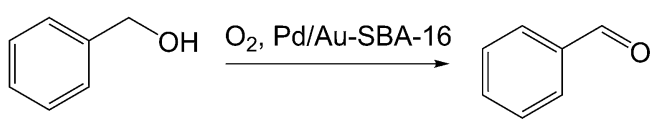

Scheme 17 Catalytic oxidation of benzyl alcohol to benzaldehyde. 


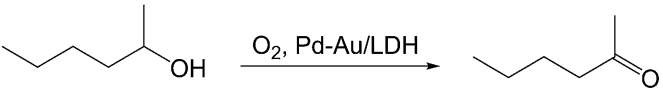

Scheme 18 Catalytic oxidation of 1-methyl-1-pentanol to butyl methyl ketone.

and $(\mathrm{EtO})_{3} \mathrm{SiBu}-t$. The modified supports were loaded with $\mathrm{PdCl}_{2}$, reduced with hydrogen and then tested in aerobic oxidation of neat benzyl alcohol and other alcohols to the corresponding aldehydes. The catalytic results revealed that the type and the amount of functional groups used for functionalization of the TUD-1 support greatly affect the catalytic performance. TUD-1 appropriately surface-covered by APTES coverage displayed the best results (TOF about $18500 \mathrm{~h}^{-1}$ for benzyl alcohol oxidation) owing to the enhanced metal-support interaction and finely tuned local surface basicity around the Pd nanoparticles.

Lee et $a l .{ }^{179}$ reported the synthesis of hierarchically ordered ( $270 \mathrm{~nm}$ macropores and $5 \mathrm{~nm}$ mesopores) materials with SBA15 architecture with further post-synthetic impregnation with palladium. Bulk and surface characterization revealed that incorporation of complementary macropores into mesoporous SBA-15 improve the dispersion of sub-2 $\mathrm{nm}$ Pd nanoparticles and thus increase the degree of their surface oxidation. The catalysts were employed in aerobic selective oxidation of sterically different allylic alcohols, in particular bulky phytol (Scheme 19). Kinetic profiling suggested a relationship between nanoparticle dispersion and oxidation rate, identifying surface $\mathrm{PdO}$ as the catalytically active phase. Rates of selective oxidation of crotyl and cinnamyl alcohols (relatively smaller representatives) over these hierarchical catalysts were superior to those observed for analogous Pd catalyst deposited over mesoporous SBA-15 at equivalent Pd loading, irrespective of whether the micropores were present within the latter support. However, the hierarchical and purely mesoporous supports exhibited identical TOFs with each of these small alcohols. This contrasts with the trends observed for long chain allylic alcohols, where the excellent activity of Pd supported on hierarchical SBA-15 was evidenced by increased TOFs with respect to $\mathrm{Pd} /$ mesoporous SBA-15 (1502 vs. $480 \mathrm{~h}^{-1}$ for farnesol, and 1258 vs. $252 \mathrm{~h}^{-1}$ for phytol). Therefore, authors assumed that hierarchical nanoporous Pd-catalyst outperforms mesoporous analogues in allylic alcohol selective oxidation by stabilizing PdO nanoparticles and by improving in-pore diffusion and access to active sites for relatively bulky aliphatic substrates such as farnesol or phytol.

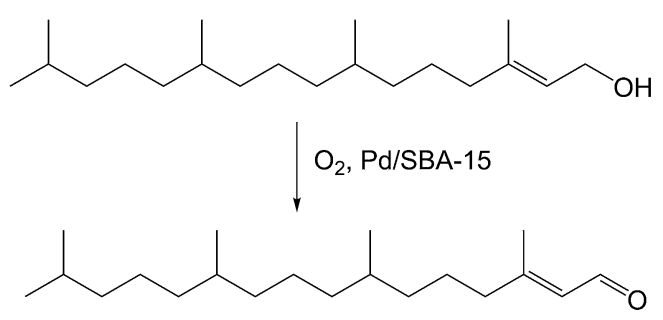

Scheme 19 Selective oxidation of phytol.
Karimi et al. ${ }^{180}$ modified SBA-15 with bis(2-pyridyl)amide groups and loaded this support with palladium(II) acetate. The resulting material was utilised as a catalyst for oxidation of primary and secondary alcohols to the respective carbonyl compounds with air or pure oxygen. The catalyst showed high efficiency and could be recovered without any decrease in activity. A following study ${ }^{181}$ compared this catalyst with analogous supported catalyst resulting by condensation of 3-aminopropyl silica with 2-acetylpyridine or bis(2-pyridyl)ketone and palladation of the respective 3 -iminopropylated supports. Using TEM analysis of the samples before and after catalysis, authors demonstrated that the nature of the ligand can affects the generation of nanoparticles in palladium catalyst deposited on hybrid amorphous silica. In the case of aerobic oxidation reactions using supported palladium catalyst on hybrid SBA- 15 , the combination of organic ligand and ordered mesoporous channels synergistically enhanced the overall catalytic activity, prevented aggregation of Pd nanoparticles and thus enabled the generation of a durable catalyst. Catalysts prepared with different types of bidentate ligands exhibited high efficiency (e.g., in the oxidation of 1-phenylethanol to acetophenone at $150{ }^{\circ} \mathrm{C}$ under solvent-free conditions they reached TOFs of more than $18000 \mathrm{~h}^{-1}$ ).

A similar terminal modifying group was employed by Leitner and co-workers, ${ }^{182}$ who prepared [3-(bis(2-pyridyl)amino)propyl] triethoxysilane and condensed this reagent with TEOS in the presence of $n$-decylamine. The obtained functional siliceous material was loaded with palladium(II) acetate and reduced with benzyl alcohol $\left(110^{\circ} \mathrm{C}\right)$ or hydrogen $\left(40 \mathrm{bar}, 110^{\circ} \mathrm{C}\right)$ to give a deposited $\operatorname{Pd}(0)$ catalyst, which was carefully characterised and found to be active in aerobic oxidation of alcohols in supercritical $\mathrm{CO}_{2}$. The observed high activity of Pd nanoparticles supported on mesoporous organic-inorganic hybrid materials was explained by the presence of small primary crystallites (approx. $2 \mathrm{~nm}$ ) that conglomerate to assemblies of about $25 \mathrm{~nm}$ in size, thereby leading to metal particles with a larger number of high-indexed planes in small volume units.

A Pd-catalyst deposited on a guanidine-modified support was obtained using mesoporous molecular sieve SBA-16, 1,1,3,3tetramethyl-2-[3-(trimethoxysilyl)propyl]guanidine, $\quad\left(\mathrm{Me}_{2} \mathrm{~N}\right)_{2}$ $\mathrm{C}=\mathrm{N}\left(\mathrm{CH}_{2}\right)_{3} \mathrm{Si}(\mathrm{OMe})_{3}$, and a palladium(II) source. ${ }^{183}$ Catalytic properties of the resulting material were evaluated in aerobic oxidation of benzylic alcohols and cinnamyl alcohol, affording the products in $94-99 \%$ yields and $>99 \%$ selectivity. The catalyst could be reused 15 times without any notable decrease in its activity and selectivity. A related catalyst based on periodic mesoporous hybrid material with a palladium-guanidine complex was synthesised in the presence of $\mathrm{CTAB}$ as a structure-directing agent. ${ }^{184}$ The resulting material exhibits a 2D-hexagonal structure with well-developed porous system, into which Pd-guanidine complex was covalently integrated. The resulting mesoporous catalyst was similarly tested in oxidation of benzylic alcohols under atmospheric pressure of $\mathrm{O}_{2}$, exhibiting high conversion and selectivity (up to $99 \%$ ). 


\section{Reduction of nitro compounds}

Aminoaromatics produced by the hydrogenation of corresponding nitro precursors are important commodity chemicals employed in the synthesis of numerous industrially important products such as agrochemicals, pharmaceuticals and dyes. ${ }^{185,186}$ Therefore, a number of researchers have focused on the selective reduction of nitro-compounds to the respective amines and other reduced derivatives mediated by deposited palladium catalysts.

Recently, the treatment of MCM-41 with $(\mathrm{MeO})_{3} \mathrm{Si}_{(}\left(\mathrm{CH}_{2}\right)_{3}{ }^{-}$ $\mathrm{NHCH}_{2} \mathrm{CH}_{2} \mathrm{NH}_{2}$ and, subsequently, with $\left[\mathrm{PdCl}\left(\eta^{3}-\mathrm{C}_{3} \mathrm{H}_{5}\right)\right]_{2}$ were used to prepare a catalyst, which was successfully tested in hydrogenation of isomeric chloronitrobenzenes to chloroanilines (Scheme 20), showing only a low dehydrohalogenation. ${ }^{187,188}$ The prepared catalyst was found to be highly active with reasonable selectivities, performing better than its commercial analogue (Pd supported on $\mathrm{Al}_{2} \mathrm{O}_{3}$ ).

El-Sheikh et al. ${ }^{189}$ reported the synthesis of nanocomposite Pd-catalysts based on SBA-15 using two different reduction routes (under $\mathrm{H}_{2}$ and using sodium citrate) and compared them with $\mathrm{Au}$ and Pt-analogues. In all the catalysts, metal nanoparticles with size $<30 \mathrm{~nm}$ were produced inside the SBA-15 pores as well as at the external walls. Catalytic efficiency of the synthesised nanocomposites was tested in the reduction of 4-nitrophenol to 4-aminophenol (Scheme 21). It was found, that the catalytic activity strongly depends on the synthetic route. Two efficiency trends were observed: $\mathrm{Pd}>\mathrm{Pt}>\mathrm{Au}$ for the $\mathrm{H}_{2-}$ reduced materials, and $\mathrm{Au}>\mathrm{Pt}>\mathrm{Pd}$ for those obtained via the sodium citrate route. The highest reaction rate was observed in the case of $\mathrm{Pd}$ nanoparticles prepared by reduction with $\mathrm{H}_{2}$ with a rate constant of $0.715 \mathrm{~s}^{-1}$.

3-Aminopropyl and 3-mercaptopropyl groups were used to modify surface of various composite catalyst, e.g., silica-coated magnetic $\mathrm{Fe}_{2} \mathrm{O}_{3}$ nanoparticles. ${ }^{190}$ After metalation with palladium(II) acetate, these particles were used as magnetically separable and recyclable catalyst for catalytic hydrogenation of nitrobenzene to aniline (Scheme 22). Pd nanoclusters were shown to be deposited with high dispersion and stability, especially when $[N$-(2-aminoethyl)-3-aminopropyl]trimethoxysilane was used as the anchoring agent. The catalyst prepared with this $\mathrm{N}$-containing modifier showed the highest conversion rate of $0.39 \mu \mathrm{mol} \mathrm{s}^{-1}$ while its S-analogue bearing 3-mercaptopropyl groups and commercial Pd carbon-supported catalyst exhibited conversion rates of only 0.12 and $0.08 \mu \mathrm{mol} \mathrm{s}^{-1}$, respectively.

Further examples of the use of silica-coated magnetic supports were provided by Ma et al., who described a method to stabilise $\operatorname{Pd}(0)$ particles either on the surface of hollow magnetic mesoporous spheres with $\mathrm{Fe}_{3} \mathrm{O}_{4}$ nanoparticles embedded in the

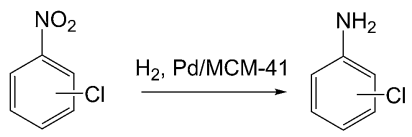

Scheme 20 Hydrogenation of isomeric chloronitrobenzenes to the corresponding chloroanilines.

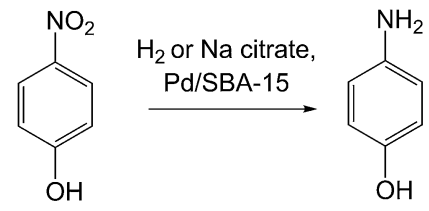

Scheme 21 Reduction of 4-nitrophenol into 4-aminophenol.

mesoporous shell ${ }^{191}$ or on amine-functionalised magnetite nanoparticles. ${ }^{192}$ The hydrogenation of a set of nitro compounds was performed under mild conditions $\left(1 \mathrm{~atm} \mathrm{H}_{2} / 25{ }^{\circ} \mathrm{C}\right.$ ) with $96-99 \%$ yields after $60 \mathrm{~min}$. It was shown, that such catalysts can be easily magnetically separated and reused for up to five successive hydrogenation reactions without change in substrate conversion. The recyclability of the catalyst was attributed to the efficient stabilization of the active Pd metal by the amine groups on the surface of hollow magnetic mesoporous spheres. Commercial $10 \% \mathrm{Pd} / \mathrm{C}$ catalyst required significantly longer reaction time under the same conditions.

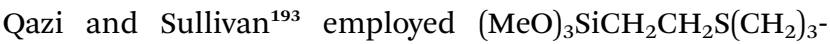
$\mathrm{S}\left(\mathrm{CH}_{2}\right)_{2} \mathrm{Si}(\mathrm{OMe})_{3}$ to modify porous silicas with different pore sizes (5, 7 and $14 \mathrm{~nm}$ average diameter) and to prepare Pdcatalysts for hydrogenation of nitrobenzene to aniline (see Scheme 22). In contrast to expectations based on diffusion issues, conversion decreased with increase of the average pore size while it simultaneously increased with the growth of surface area. Catalyst with the smallest average pore size (5 nm), the narrowest pore size distribution and the highest surface area displayed the best kinetic profile, achieving complete reduction within $60 \mathrm{~min}$ at $10 \mathrm{~atm} \mathrm{H}_{2}$ and $50^{\circ} \mathrm{C}$, while reactions over catalysts with 7 and $14 \mathrm{~nm}$ channels reached $100 \%$ conversion in 80 and $120 \mathrm{~min}$, respectively. The palladium surface loadings $\left(1.3 \mathrm{mmol} \mathrm{m}^{-2}\right.$ for material with $5 \mathrm{~nm}$ pores, $2.1 \mathrm{mmol} \mathrm{m}^{-2}$ for $7 \mathrm{~nm}$ pores, and $2.3 \mathrm{mmol} \mathrm{m}^{-2}$ for $14 \mathrm{~nm}$ pores) suggest a greater degree of site isolation in the smallestpore material, which could be play an important role in controlling the conversion efficiency. The use of commercial Pd/ C $(10 \%)$ also resulted in complete conversion to aniline. However, leaching tests of the filtrate revealed that $24 \%$ of the $\mathrm{Pd}$ had leached from Pd/C in contrast to the negative leaching tests for all prepared catalysts as measured by the standard hot filtration tests and analysis for Pd in filtrate by ICP-OES measurements.

Yasuda et al. ${ }^{194}$ prepared a set of Pd catalysts supported on various silicas including mesoporous and non-porous ones aiming at an elucidation of activity-controlling factors in selective hydrogenation of 1-nitrohexane to $N$-hexyl hydroxylamine (Scheme 23). The Pd catalysts supported on non-porous silica or silicas that possessed large pores efficiently produced

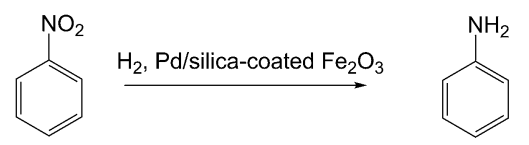

Scheme 22 Catalytic hydrogenation of nitrobenzene to aniline. 
the target product in high yields (89-96\%). Based on this observation, the authors concluded that the influence of pore diffusion was small. On the other hand, the catalytic activity was strongly depended on the Pd dispersion, decreasing generally with the increased Pd dispersion (or the decreased Pd particle size).

A heterogeneous catalytic assembly consisting of Pd nanoparticles on silica support and ionic liquid multi-imidazolium brushes has been developed by Chen et al. ${ }^{195}$ The uniform Pd particles size distribution (from 0.5 to $1.5 \mathrm{~nm}$ ) has been found in these materials, which mediated the hydrogenation of various nitroarenes to arylamines with almost $100 \%$ yield and selectivity under solvent-free conditions at room temperature and atmospheric pressure. Notably, the catalyst even facilitated the transformation of solid water-insoluble nitrobenzenes with complete conversions albeit at a lower rate. The performance of these material was compared with those reported in the literature, ${ }^{196,197}$ indicating much higher efficiency of the catalyst combining the advantages of an ionic liquid, Pd nanoparticles and a heterogeneous catalyst.

\section{Hydrogenation of unsaturated compounds}

Hydrogenation of unsaturated double and triple bonds is among the most important processes in laboratory synthesis as well as in petrochemical, pharmaceutical and food industries. ${ }^{198,199}$ These reactions typically require control of the selectivity and, hence, careful catalyst design. ${ }^{200}$ In order to prepare a series of supports surface-functionalised with $\equiv \mathrm{Si}\left(\mathrm{CH}_{2}\right)_{3} \mathrm{NHCH}_{2} \mathrm{CH}_{2} \mathrm{NH}_{2}$ groups, Shimazu and co-workers ${ }^{201}$ treated mesoporous molecular sieve MCM-41 or silica (Aerosil $200)$ with (EtO $)_{3} \mathrm{Si}\left(\mathrm{CH}_{2}\right)_{3} \mathrm{NHCH}_{2} \mathrm{CH}_{2} \mathrm{NH}_{2}$. MCM-41-based support was further trimethylsilylated and all solid supports were loaded with palladium(II) acetate. The resulting materials were tested as catalysts for regioselective hydrogenation of nonconjugated terpenic dienes (Scheme 24). The best results were obtained with Pd-catalysts based on aminated MCM-41 and silica; catalyst prepared from the silylated MCM-41 support exerted a lower activity. Furthermore, dienes possessing hydroxyl groups in their structure were hydrogenated faster than limonene, which was attributed to supportive interactions of the $\mathrm{OH}$ group in the substrate and those present on the support surface.

Repeated Michael addition of methyl acrylate to aminopropyl-SBA-15 and amidation reactions of the ester

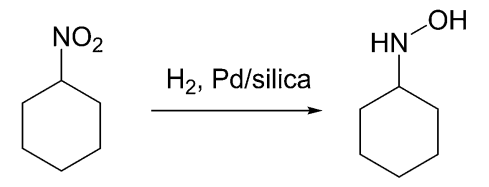

Scheme 23 Selective hydrogenation of 1-nitrohexane to $\mathrm{N}$-hexyl hydroxylamine. groups with 1,2-diaminoethane were used to construct poly(amino-amine) dendrimers at the solid support and the resulting hybrid materials were used for immobilization of in situ generated Pd nanoparticles. The nanoparticle catalysts were tested in hydrogenation of allyl alcohol to 1-propanol (Scheme 25), showing higher activities (TOF up to $2300 \mathrm{~h}^{-1},>99 \%$ conversion, selectivity up to $91 \%$ ) than catalysts based on dendrimer-encapsulated Pd nanoparticles. Selectivity of the reaction increased with increasing size (generation) of the hyperbranched modifier. ${ }^{202}$

Another composite catalyst was prepared by $\mathrm{Wu}$ et al. $^{\mathbf{2 0 3}} \mathrm{via}$ deposition of Pd nanoparticles onto aminopropylated silica and subsequent covering of these particles with polystyrene. As catalysts, the resulting materials showed good activities in hydrogenation of 2,4-dimethyl-1,3-pentadiene to 2,4-dimethyl2-pentene (Scheme 26) and allyl alcohol to 1-propanol (Scheme 25) performed in supercritical $\mathrm{CO}_{2}$. The authors suggested that the polymer coating in the catalysts suppresses the rate of isomerization of allyl alcohol during the hydrogenation reaction by altering both the environment of active sites and access to these active sites, similar to the function of dendrimers $^{204}$ or polyelectrolyte multilayers. ${ }^{205}$ This positively affects the selectivity of the reduction while supercritical $\mathrm{CO}_{2}$ increases the reaction rates.

Han et al. ${ }^{206}$ synthesised a $\mathrm{Pd}(\mathrm{II})$-loaded material from mesoporous silica modified by $\mathrm{N}$-heterocyclic carbene ionic liquids with different alkyl chain lengths and tested them in hydrogenation of alkenes and allyl alcohol. The activity of the catalysts in the reduction of allyl alcohol was similar to that of commercial $\mathrm{Pd} / \mathrm{C}$ catalyst, while in hydrogenation of 1-hexene and cyclohexene, the efficiency was lower than that of $\mathrm{Pd} / \mathrm{C}$. Nonetheless, the selectivities to 1-propanol were in the range $80-85 \%$, which is higher than those obtained using the commercial $\mathrm{Pd} / \mathrm{C}$ catalyst (74\%). This may indicate that the ionic liquids can not only immobilize the metal catalyst, but also enhance the selectivity of the reaction. The steric hindrance of the prepared catalysts was expected to increase with the length of the alkyl chain present in the ionic liquid residua leading to an increase in reaction selectivity, but when the chain length was longer than $\mathrm{C}_{10}$, the selectivity to 1-propanol was not changed any further, presumably because the effective steric hindrance reaching a sort of limiting value.

Ying et $a .^{207}$ reported the synthesis of palladium nanoparticles supported on siliceous mesocellular foam using $(\mathrm{MeO})_{3} \mathrm{Si}\left(\mathrm{CH}_{2}\right)_{3} \mathrm{NHCONH}_{2}$ or $(\mathrm{MeO})_{3} \mathrm{Si}\left(\mathrm{CH}_{2}\right)_{3} \mathrm{NHCONH}\left(\mathrm{CH}_{2}\right)_{3}$ $\mathrm{Si}(\mathrm{OMe})_{3}$ as the modifiers. The resulting materials were tested in hydrogenation reaction of activated olefins under relatively low hydrogen pressure (2.5 atm) and room temperature. The target products were obtained in excellent yields (quantitatively) and the catalyst was successfully recycled and reused for 10 runs without loss in activity.

Angelici et al. $^{208}$ prepared air-stable heterogeneous $\mathrm{Pd} / \mathrm{Rh}$ catalysts showing good activities in hydrogenation of arenes under atmospheric pressure. Similar catalysts were synthesised by treatment of $\mathrm{Pd} / \mathrm{SiO}_{2}$ with $\left[\mathrm{Rh}_{2}(\mu-\mathrm{SR})_{2}\left(\mathrm{Ph}_{2} \mathrm{PR}_{2}\right)_{2}(\mathrm{CO})_{2}\right]$ $\left(\mathrm{R}=\left(\mathrm{CH}_{2}\right)_{3} \mathrm{Si}(\mathrm{OMe})_{3}, \mathrm{R}^{\prime}=\left(\mathrm{CH}_{2}\right)_{3} \mathrm{Si}(\mathrm{OEt})_{3}\right)$. The resulting 
<smiles>CC(C)=CCCC(C)=CCO</smiles><smiles>CC(C)=CCCC(C)CCO</smiles><smiles>C/C(=C/CO)CCCC(C)C</smiles><smiles>[TeH][Ba]</smiles><smiles>CC(C)CCCC(C)CCO</smiles><smiles>C=CC(C)(O)CCC=C(C)C</smiles><smiles>CCC(C)(O)CCC=C(C)C</smiles><smiles>C=CC(C)(O)CCCC(C)C</smiles>

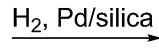<smiles>CCC(C)(O)CCCC(C)C</smiles><smiles>C=C(C)C1CC=C(C)CC1</smiles><smiles>C=C(C)C1CCC(C)CC1</smiles><smiles>CC1=CCC(C(C)C)CC1</smiles><smiles>CC1CCC(C(C)C)CC1</smiles>

Scheme 24 Hydrogenation of non-conjugated terpenic dienes.

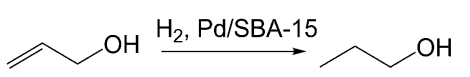

Scheme 25 Hydrogenation of allyl alcohol to 1-propanol.

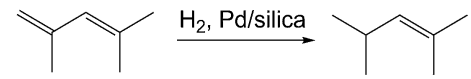

Scheme 26 Hydrogenation of 2,4-dimethyl-1,3-pentadiene to 2,4dimethyl-2-pentene.

complexes tethered on Pd-loaded silica were evaluated as catalysts for hydrogenation of arenes. ${ }^{209}$ More recently, Mou and co-workers ${ }^{\mathbf{2 1 0}}$ synthesised and characterised silicasupported Pd "single-atom alloy" by decreasing the loading of Pd to the ppm level when alloying Pd with gold nanoparticles at about $3 \mathrm{~nm}$ and applied it to selective hydrogenation of acetylene in the presence of an excess of ethylene. The conversion of acetylene was found to decrease while the selectivity to ethylene increased with decreasing Pd loading. When the temperature was raised from $80{ }^{\circ} \mathrm{C}$ to $160{ }^{\circ} \mathrm{C}$, the selectivity for ethylene increased by about 10-times as compared to the monometallic $\mathrm{Pd} / \mathrm{SiO}_{2}$ catalyst with similar, ppm-level Pd loading. This was explained by a weaker adsorption of ethylene on the Pd "singleatom alloy" compared with the monometallic $\mathrm{Pd} / \mathrm{SiO}_{2}$ catalyst. The Pd in the fabricated structure was hold responsible for the increased reactivity, while the Au is believed to play a key role in isolating the Pd atoms and preventing the over-hydrogenation of acetylene.

The preparation of $\operatorname{Pd}(0)$ nanoparticle catalyst supported by an aminopolymer-silica composite was reported by Jones et $a .^{211}$ Small palladium nanoparticles with a narrow distribution were generated through reduction of $\mathrm{Pd}(\mathrm{II})$ species and loaded into a mesoporous silica material functionalised with branched poly(ethyleneimine) (PEI) polymers. The resulting catalysts exhibited high activity in hydrogenation of diphenylacetylene to selectively produce cis-stilbene (Scheme 27) under mild conditions. It was found that the rate of over-hydrogenation could be significantly reduced by increasing the support porosity and by using a highmolecular-weight polymer. These single-component catalysts could be easily recovered and recycled with no leaching of palladium detectable, retaining their high activities and selectivity over several cycles.

Rhee and co-workers ${ }^{212}$ prepared Pd particles (2-4 $\mathrm{nm}$ in size) dispersed on two types of solid supports (3-aminopropyl functionalised silica gel and cross-linked poly(4-vinylpyridine-co-styrene) gel). The reactivity of obtained catalysts was evaluated in hydrogenation of various $\alpha, \beta$-unsaturated carbonyl compounds. Both catalysts exhibited high yields of the $\mathrm{C}=\mathrm{C}$ bond hydrogenation products (95-100\% in $0.5-6$ h), although Pd dispersed on silica was more efficient than Pd dispersed on the polymer. The lower reactivity of latter catalyst was attributed to its structure, assuming that the pyridyl units of the polymer surrounded the Pd making it less accessible for catalysis.

\section{Dehalogenation}

In 1986, Nesterov et al. ${ }^{\mathbf{2 1 3}}$ communicated that palladium catalysts prepared from silica gel modified by imine groups of the type $\mathrm{RCH}=\mathrm{N}\left(\mathrm{CH}_{2}\right)_{3} \mathrm{Si} \equiv$, where $\mathrm{R}$ is 2-, 3- and 4-pyridyl, 2-pyrryl, 2-thienyl, and 2-furyl, are active in hydrodehalogenation of chloro-nitrobenzenes to nitrobenzene. Another interesting

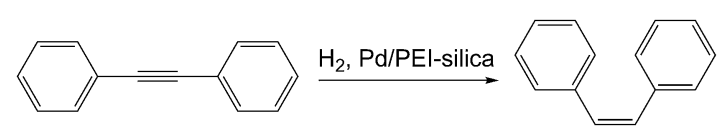

Scheme 27 Hydrogenation of diphenylacetylene to cis-stilbene. 
concept was coined by Angelici et al. ${ }^{214}$ who prepared pyridylphosphine and 2,2'-bipyridine ligands equipped with functional 3-(trialkoxysilyl)propyl tags and their cationic $\mathrm{Rh}(\mathrm{I})$ $\left(\eta^{2}: \eta^{2}\right.$-cycloocta-1,5-diene) complexes. These complexes were subsequently reacted with silica-supported palladium (obtained by impregnation of $\mathrm{SiO}_{2}$ with $\mathrm{H}_{2}\left[\mathrm{PdCl}_{4}\right]$, calcination and reduction with $\mathrm{H}_{2}$ ) to afford a mixed metal deposited catalyst, which exhibited reasonable activity (TON in the range 750-850) in hydrogenative defluorination of fluorobenzene to give cyclohexane (Scheme 28) and in similar reaction of 1,2difluorobenzene.

Albonetti et al. ${ }^{215}$ prepared a series of bimetallic mesostructured $\mathrm{Pd} / \mathrm{Cu}$ MCM- 41 catalysts by impregnation with Pd precursors and direct hydrothermal synthesis using different silica sources. The catalysts were tested in hydrogenative dechlorination of a fluorinated substrate (Scheme 29). The incorporation of $\mathrm{Pd}$ and $\mathrm{Cu}$ during the course of MCM-41 synthesis, regardless of the hydrothermal treatment, did not destroy the typical hexagonal channel array and ordered pore system of the parent MCM-41. However, the calcination for the removal of the template led to a segregation of metal oxides, and thus large $\mathrm{Pd} / \mathrm{Cu}$ bimetallic particles were obtained after reduction. The impregnation led to pore occlusion, more pronounced for the sample obtained from silicates as silica source. After the reduction, both isolated monometallic $\mathrm{Cu}$ particles and large bimetallic $\mathrm{Pd} / \mathrm{Cu}$ particles were found to coexist on the external surface of the support. A lower conversion of $\mathrm{CF}_{3} \mathrm{OCFClCF}_{2} \mathrm{Cl}$ was achieved with catalyst possessing larger metallic particles, while the presence of monometallic particles decreased the selectivity to the target fluorinated ether.

Another active catalyst obtained by depositing palladium(II) acetate over SBA-15 type sieve equipped with the $\equiv \mathrm{SiCH}_{2} \mathrm{CH}_{2}{ }^{-}$ $\mathrm{CH}_{2} \mathrm{NHCH}_{2} \mathrm{CH}_{2} \mathrm{NEt}_{2}$ groups ${ }^{216}$ was used in reductive dehalogenation of aryl halides with in situ generated trimethylammonium formate (Scheme 30). The reaction proceeded efficiently with aryl bromides and iodides (better than with $\mathrm{Pd} / \mathrm{C}$ ) and with only a minor leaching of Pd. Chlorobenzenes reacted at considerably slower reaction rates while aromatic fluorides remained unaffected, which allowed for selective removal of the more reactive (i.e., heavier) halide from unsymmetrical dihaloarenes.

\section{Other reactions}

Catalyst obtained by deposition of palladium(II) acetate onto SBA-15 type support modified by $(\mathrm{MeO})_{3} \mathrm{Si}\left(\mathrm{CH}_{2}\right)_{3^{-}}$ $\mathrm{NHCH}_{2} \mathrm{CH}_{2} \mathrm{NH}_{2}$ and silylated with chloro-trimethylsilane was employed in addition of allyl chlorides to aldehydes and ketones to give homoallylic alcohols (Scheme 31 ). ${ }^{217}$ The reactions

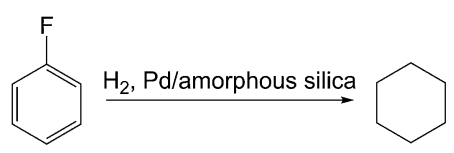

Scheme 28 Hydrogenative defluorination of fluorobenzene.

$$
\underset{\mathrm{F}_{3} \mathrm{C}-\mathrm{O}^{\mathrm{FC}-\mathrm{CF}_{2}} \stackrel{\mathrm{H}}{\mathrm{Cl}} \stackrel{\mathrm{Cl}}{\mathrm{C}} \mathrm{Pd}-\mathrm{Cu} / \mathrm{MCM}-41}{\longrightarrow} \mathrm{F}_{3} \mathrm{C}-\mathrm{O}^{\mathrm{FC}}=\mathrm{CF}_{2}
$$

Scheme 29 Hydrogenative dechlorination of trifluoromethyl 1,2dichloro-1,2,2-trifluoroethyl ether to trifluoromethyl trifluorovinyl ether.

proceeded well with various substrates at $2 \mathrm{~mol} \% \mathrm{Pd}$ loading in the presence of $\mathrm{SnCl}_{2}$ as a stoichiometric additive.

Alkylation reaction of 3-chloropropylated SBA-15 with 1,4diazabicyclo[2.2.2] octane (dabco) afforded another support bearing 3-(1-azonia-4-azabicyclo[2.2.2] octane)propyl groups at the surface. Catalyst obtained after deposition of palladium(II) acetate and combined with CuI co-catalyst (both $1 \mathrm{~mol} \%$ ) efficiently mediated oxidative coupling of various terminal alkynes to the corresponding 1,3-butadiynes (Scheme 32). ${ }^{\mathbf{2 1 8 , 2 1 9}}$

Tsai and co-workers prepared a $\operatorname{Pd}(\mathrm{II})-2,2^{\prime}$-bipyridine complex possessing two anchoring triethoxysilyl groups and grafted this complex onto nanosized MCM-41. The resulting anchored complex was successfully applied as a highly efficient and recyclable catalyst for Kumada coupling of arylmagnesium halides with aryl halides to give biaryls (Scheme 33) ${ }^{220}$ and in arylation of acyl chlorides with triarylbismuth reagents leading to ketones (Scheme 34). ${ }^{221}$

A rather specific class of immobilised catalytic systems was introduced by Alper, ${ }^{222,223}$ who constructed ${ }^{224}$ amido-amine dendrimers (up to the fourth generation) at silica and modified them with metal-binding donor groups at the terminal positions (typically $\left.-\mathrm{N}\left(\mathrm{CH}_{2} \mathrm{PPh}_{2}\right)_{2}\right)$. The resulting anchored ligands were extensively evaluated in various Pd-catalysed processes such as hydroesterification of alkenes (Scheme 35). ${ }^{225}$ A similar catalyst was prepared also with pincer-type ligating moieties and Pd/PCP terminal groups. ${ }^{226}$

Li et al. prepared a series of Pd-catalysts deposited over periodic mesoporous organosilica modified with 2-(diphenyphosphino)ethyl groups by surfactant-directed co-condensation of 1,4-bis(triethoxylsilyl)benzene (or 4,4'-bis(triethoxysilyl) biphenyl) with the pre-formed $\mathrm{Pd}(\mathrm{II})$ complex $\left[\mathrm{PdCl}_{2}\left\{\mathrm{Ph}_{2} \mathrm{PCH}_{2}\right.\right.$ $\left.\left.\mathrm{CH}_{2} \mathrm{Si}(\mathrm{OEt})_{3}-\kappa P\right\}_{2}\right]$ in the presence of $\mathrm{P} 123$ triblock copolymer or, alternatively, via post-synthetic palladation of a periodic mesoporous organosilica support prepared by co-condensation of [2-(diphenylphosphino)ethyl]triethoxysilane with 1,4-bis(triethoxylsilyl)benzene. ${ }^{27}$ Catalysts based on SBA-15 were obtained in a similar manner from $\left[\mathrm{PdCl}_{2}\left\{\mathrm{Ph}_{2} \mathrm{PCH}_{2} \mathrm{CH}_{2}\right.\right.$ $\left.\left.\mathrm{Si}(\mathrm{OEt})_{3}-\kappa P\right\}_{2}\right] / \mathrm{Si}(\mathrm{OEt})_{4} / \mathrm{P} 123$ or from $\left[\mathrm{PdCl}_{2}\left\{\mathrm{Ph}_{2} \mathrm{PCH}_{2} \mathrm{CH}_{2}-\right.\right.$ $\left.\left.\mathrm{Si}(\mathrm{OEt})_{3}-\kappa P\right\}_{2}\right] / \mathrm{Si}(\mathrm{OEt})_{4} / \mathrm{PhSi}(\mathrm{OMe})_{3} / \mathrm{P} 123$. The resulting materials were tested in allylation of benzaldehyde (Scheme 36) using water as the reaction medium. Catalysts based on

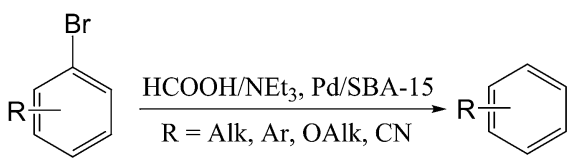

Scheme 30 Reductive dehalogenation of aryl bromides. 


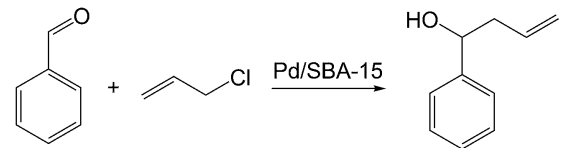

Scheme 31 Representative addition of allyl chloride to benzaldehyde.

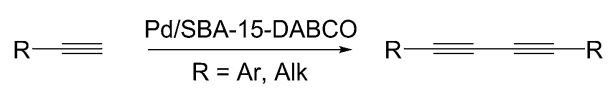

Scheme 32 Oxidative coupling of terminal alkynes to the corresponding 1,3-butadiynes.

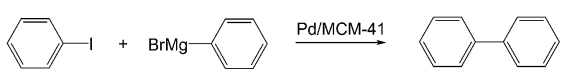

Scheme 33 Kumada coupling of arylmagnesium halides with aryl halides.

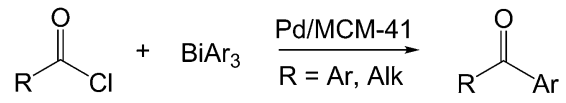

Scheme 34 Arylation of acyl chlorides with triarylbismuth derivatives.

$$
\stackrel{\mathrm{R}}{\mathrm{C}} \underset{\mathrm{R}=\mathrm{Ar} \text {, Alk }}{\stackrel{\mathrm{CO}, \mathrm{Pd} / \text { silica }}{\longrightarrow}} \stackrel{\mathrm{R}}{\mathrm{R}}
$$

Scheme 35 Hydroesterification of alkenes with methanol affording methyl esters.

periodic mesoporous organosilica typically showed higher activities than those derived from SBA-15, often comparable with $\left[\mathrm{PdCl}_{2}\left(\mathrm{PPh}_{3}\right)_{2}\right]$ as their homogenous counterpart. ${ }^{228-230}$

A series of mesoporous siliceous materials with different pore structures and the donor 2-(diphenylphosphino)ethyl substituents was obtained by hydrolysis and condensation under solvothermal conditions of a mixture containing TEOS, [2-(diphenylphosphino)ethyl]triethoxysilane ( $c a .3-13 \%$ of total $\mathrm{Si}$ in the reaction mixture) and various structure-directing agents. ${ }^{231}$ Upon treatment with palladium(II) acetate, these supports were converted to deposited Pd-catalysts, which were tested in allylation of styrene oxide (Scheme 37). The reaction performed in the presence of indium(I) chloride ( 2.2 equiv.) afforded the desired product in $c a .60-80 \%$ yields.

Moreau et al. ${ }^{232}$ prepared a nanostructured silica by direct hydrothermal condensation of TEOS with dimethyl(4-pyridyl)<smiles>C=CCC(O)c1ccccc1</smiles>

Scheme 36 Allylation of benzaldehyde with allyl bromide. [(3-triethoxylsilyl)propyl]ammonium iodide in the presence of 1-dodecyl-3-methylimidazolium bromide as the structure directing agent. Supported catalysts obtained after treatment with palladium(II) acetate achieved good catalytic results (76$78 \%$ yields) in cyanation (Scheme 38) of aromatic halides with potassium hexacyanoferrate(II).

Furthermore, Pd catalysts deposited over mercaptopropylated MCM-41 were evaluated in Stille reaction (Scheme 39) of organostannanes with aryl halides to give the respective biaryls or arylalkanes in reasonable to very good yields $(70-90 \%$ after $5 \mathrm{~h}$, TOFs up to $\left.30 \mathrm{~h}^{-1}\right) \cdot{ }^{233}$

A series of mesocelular MCF-type silica supports functionalised by treatment with $(\mathrm{MeO})_{3} \mathrm{SiCH}_{2} \mathrm{CH}_{2} \mathrm{CH}_{2} \mathrm{X}$, where $\mathrm{X}$ is $\mathrm{NH}_{2}$, $\mathrm{SH}$ and $\mathrm{NHCONH}_{2}$, and loaded with palladium(II) acetate were evaluated in Pd-catalyzed decarboxylation of stearic acid to $n$-heptadecane (Scheme 40). ${ }^{234}$ These materials reached $80-95 \%$ conversion after $6 \mathrm{~h}$ at $300{ }^{\circ} \mathrm{C}$ with $100 \%$ selectivity to the main product. Similar reaction with ethyl stearate resulted in considerably lower conversion ( $\mathrm{ca} .15 \%)$ and selectivity ( $n$-heptadecane $87 \%$, stearic acid $13 \%$ ).

Pd-catalysts deposited on silica and 3-sulfonatopropyl modified silica were tested as catalysts for the direct synthesis of hydrogen peroxide from hydrogen and oxygen, with the latter exerting better activities and selectivity. ${ }^{235}$ More recent studies were focused on similar catalysts deposited on 3-sulfonatopropyl modified mesoporous silica supports (MCM-41, MCM48, MCF, MSU-1 and SBA-15). ${ }^{236,237}$ In this case, the catalytic results were shown to be influenced by the amount of acidic groups at the support surface and by calcination temperature used during the preparation of the MCF support.

Several Pd-complexes such as $\left[\mathrm{PdCl}_{2}\left\{\left(\mathrm{Ph}_{2} \mathrm{PCH}_{2}\right)_{2}-\right.\right.$ $\left.\left.\mathrm{NCH}_{2} \mathrm{CH}_{2} \mathrm{CH}_{2} \mathrm{Si}(\mathrm{OEt})_{3}-\kappa^{2} P, P^{\prime}\right\}_{2}\right]$ and $\left[\mathrm{PdCl}_{2}\left\{\mathrm{R}_{2} \mathrm{PCH}_{2} \mathrm{CH}_{2} \mathrm{Si}(\mathrm{OEt})_{3}-\right.\right.$ $\left.\kappa P\}_{2}\right](\mathrm{R}=\mathrm{Ph}$, cyclohexyl) were covalently anchored onto mesoporous SBA-15 type silica ${ }^{238}$ and the resulting materials were studied as catalysts for the preparation of indoles from alkynes and 2-iodoaniline (Larock heteroannulation; Scheme 41). The reaction was shown to proceed in the liquid phase with the solid material serving as the source of the active metal and provided high yields of the heterocyclization product (80-85\%).

Reek et al. ${ }^{239}$ reacted silica with different trialkoxysilanefunctionalised phosphines and then silylated the unreacted $\mathrm{OH}$ groups with $\mathrm{Me}_{2} \mathrm{SiCl}_{2} / \mathrm{NEt}_{3}$. The obtained phosphinylated supports were metalated by $\left[\operatorname{Pd}(\text { dibenzylideneacetone })_{2}\right]$ and employed as catalysts in allylic substitution of allylic substrates with sodium diethyl 2-methylmalonate (Scheme 42). In the reactions with the cinnamyl substrate, all catalysts afforded preferentially the linear alkylation product (linear : branched $\approx$ $95: 5-98: 2$ ) but with different overall activities.<smiles>C=CCC(O)Cc1ccccc1</smiles>

Scheme 37 Allylation of styrene oxide. 


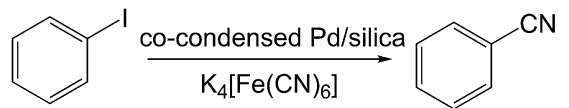

Scheme 38 Pd-catalysed cyanation of aromatic halides with potassium hexacyanoferrate(II).

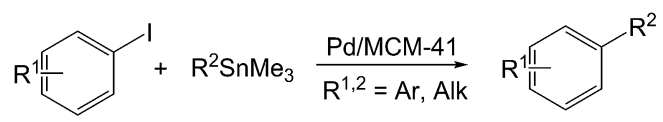

Scheme 39 Stille reaction of organostannanes with aryl halides.

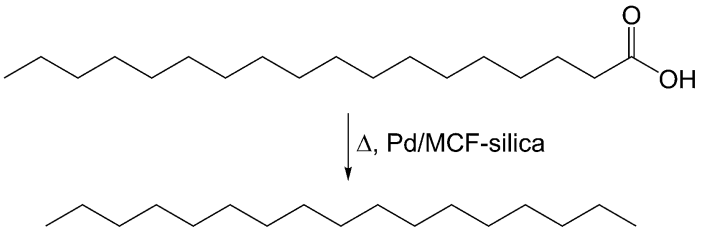

Scheme 40 Decarboxylation of stearic acid to $n$-heptadecane.

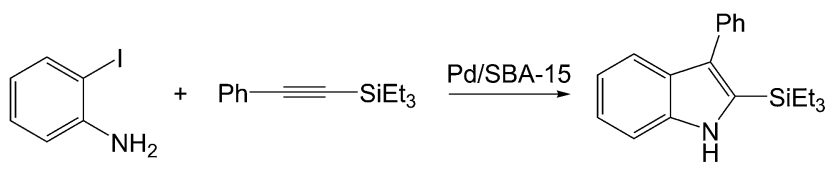

Scheme 41 Larock indole synthesis via heteroannulation.

Johnson et al. ${ }^{240}$ immobilised a chiral ferrocene diphosphine ${ }^{241}$ on mesoporous molecular sieve MCM-41 and high-area non-porous silica gel (Carbosil) via introduction of 3-bromopropyl groups followed by subsequent quarternization with the ligand's amino group. Catalysts obtained after palladation with $\mathrm{PdCl}_{2}$ were tested in asymmetric allylic amination of cinnamoyl acetate with benzylamine (Scheme 43). A comparison with the corresponding molecular catalyst showed that immobilization and the type of support affect both the regioselectivity (linear $v s$. branched product) and enantioselectivity of the allylation reaction. Whereas the molecular catalyst produced only linear product, the immobilised ones afforded $c a .50: 50$ mixture of

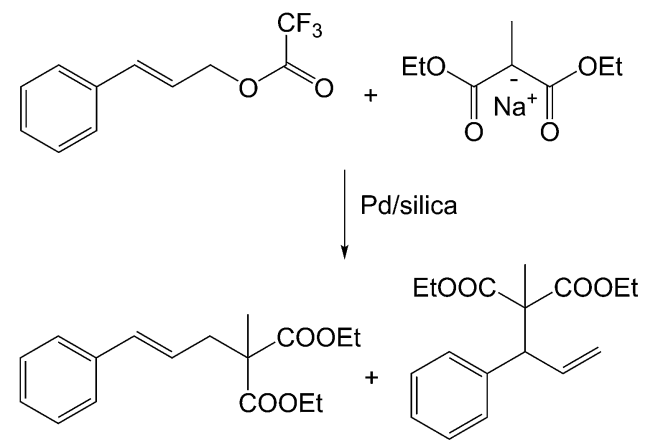

Scheme 42 Allylic substitution with diethyl 2-methylmalonate. the amination products (linear and branched; see Scheme 43). The catalyst prepared from Carbosil achieved a lower enantioselectivity (ee 43\%) than that based on MCM-41 (ee 93-99\%).

Pd pincer complexes were immobilised on silica via 3-(triethoxysilyl)carbamate groups and the resulting catalysts were tested in aldol reaction of methyl isocyanoacetate and benzaldehyde to give 4-methoxycarbonyl-5-phenyl-4,5-dihydrooxazole (Scheme 44). ${ }^{242}$ The stable conversion (92-96\%) was achieved in five consecutive catalytic cycles with unchanged high selectivity to the trans-isomer (83-84\%).

\section{Summary and outlook}

Palladium catalysts deposited over different types of silica (amorphous, mesoporous molecular sieves, solids obtained by co-condensation and many others) modified with suitable donor groups (most often with N-, S- and/or P-donor moieties) have been extensively studied due to their wide application field and favourable catalytic properties. Many catalysts reported to date show performance similar to or even superior to their homogeneous counterparts and can be reused in several reaction runs without any notable decrease of their activity and selectivity. The most often investigated processes in which these catalysts were employed are rather expectedly cross-coupling reactions that are of great practical importance due to their frequent applications in organic synthesis, typically as the crucial molecule-assembling steps. Notwithstanding, research into other reaction types such as redox processes continues apace, bringing new interesting and practically applicable results.

The possibility of fine-tuning the catalytic properties by means of the anchoring group, metal additive (in bimetallic catalysts) or through the morphology of the support makes the deposited palladium catalysts extremely versatile and thus allows for the design of purpose-tailored materials. Despite the enormous progress in the area and numerous reports published in the recent past, the catalyst design still remains far from predictable. Although the simple anchoring groups in which $-\mathrm{SH},-\mathrm{NH}_{2}$ or $-\mathrm{PPh}_{2}$ are covalently attached to the support by means of an alkyl group typically perform well or are used as starting materials for further modifications of the support surface, the search for new, more complicated modifying

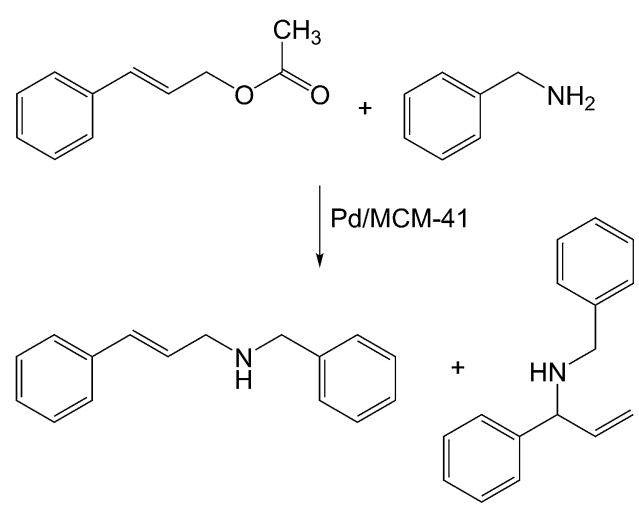

Scheme 43 Allylic amination of cinnamoyl acetate with benzylamine. 


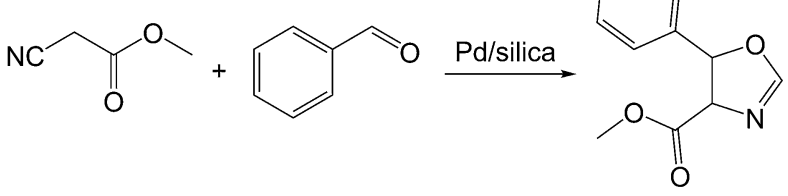

Scheme 44 Aldol reaction of methyl isocyanoacetate and benzaldehyde.

"substituents" still appears desirable in view of sought-for improvements in the catalytic efficacy (see, for instance, the promising properties of Pd catalyst deposited over supports with immobilised ionic liquids or dendrimers). Attention also should be paid to newly emerging siliceous materials with specific properties (internal structure, density etc.) that have been studied less than the already well-established ones such as conventional silica, mesoporous molecular sieves and zeolites. Alongside with the experiments aimed at the design of new catalysts and physicochemical studies into their properties, new applications (i.e., new organic processes employing these materials as catalysts) are sought for in order to fully exploit the multifaceted catalytic chemistry of immobilised palladium species.

\section{Acknowledgements}

Financial support from the Czech Science Foundation (P106/12/ G015 and 13-08890S) is gratefully acknowledged.

\section{References}

1 L. Yin and J. Liebscher, Chem. Rev., 2007, 107, 133-173.

2 Metal-Catalyzed Cross-Coupling Reactions, ed. A. de Meijere and F. Diederich, Wiley-VCH Verlag GmbH, 2nd edn, 2008.

3 J. S. Beck, J. C. Vartuli, W. J. Roth, M. E. Leonowicz, C. T. Kresge, K. D. Schmitt, C. T. W. Chu, D. H. Olson, E. W. Sheppard, S. B. McCullen, J. B. Higgins and J. L. Schlenker, J. Am. Chem. Soc., 1992, 114, 10834-10843.

4 D. Y. Zhao, Q. S. Huo, J. L. Feng, B. F. Chmelka and G. D. Stucky, J. Am. Chem. Soc., 1998, 120, 6024-6036.

5 J. C. Vartuli and T. F. Degnan Jr, Stud. Surf. Sci. Catal., 2007, 168, 837-854.

6 C. T. Kresge, M. E. Leonowicz, W. J. Roth, J. C. Vartuli and J. S. Beck, Nature, 1992, 359, 710-712.

7 D. Y. Zhao, J. L. Feng, Q. S. Huo, N. Melosh, G. H. Fredrickson, B. F. Chmelka and G. D. Stucky, Science, 1998, 279, 548-552.

8 T. Yanagisawa, T. Shimizu, K. Kuroda and C. Kato, Bull. Chem. Soc. Jpn., 1990, 63, 988-992.

9 J. M. Kim, S. K. Kim and R. Ryoo, Chem. Commun., 1998, 259-260.

10 F. Kleitz, S. H. Choi and R. Ryoo, Chem. Commun., 2003, 2136-2137.

11 S. M. Lopes dos Santos, K. A. Barros Nogueira, M. d. S. Gama, J. D. Ferreira Lima, I. J. da Silva Junior and D. C. Silva de Azevedo, Microporous Mesoporous Mater., 2013, 180, 284-292.

12 T. R. Pauly and T. J. Pinnavaia, Chem. Mater., 2001, 13, 987993.

13 J. C. Jansen, Z. Shan, L. Marchese, W. Zhou, N. von der Puil and T. Maschmeyer, Chem. Commun., 2001, 713-714.

14 S. A. Bagshaw, E. Prouzet and T. J. Pinnavaia, Science, 1995, 269, 1242-1244.

15 R. A. Pollock, B. R. Walsh, J. Fry, I. T. Ghampson, Y. B. Melnichenko, H. Kaiser, R. Pynn, W. J. DeSisto, M. C. Wheeler and B. G. Frederick, Chem. Mater., 2011, 23, 3828-3840.

16 Y. Sakamoto, T. W. Kim, R. Ryoo and O. Terasaki, Angew. Chem., Int. Ed., 2004, 43, 5231-5234.

17 A. Corma, Chem. Rev., 1997, 97, 2373-2419.

18 Y. Wang, M. Noguchi, Y. Takahashi and Y. Ohtsuka, Catal. Today, 2001, 68, 3-9.

19 L. Cao, T. Man and M. Kruk, Chem. Mater., 2009, 21, 11441153.

20 M. Widenmeyer and R. Anwander, Chem. Mater., 2002, 14, 1827-1831.

$21 \mathrm{~J}$. H. Sun and M. O. Coppens, in Nanotechnology in Mesostructured Materials, ed. S. E. Park, R. Ryoo, W. S. Ahn, C. W. Lee and J. S. Chang, 2003, vol. 146, pp. 157-160.

22 D. Zhao, Y. Wan and W. Zhou, Ordered Mesoporous Materials, Wiley-VCH Verlag GmbH \& Co. KGaA, 2013.

23 A. Corma, V. Fornes, J. M. Guil, S. Pergher, T. L. M. Maesen and J. G. Buglass, Microporous Mesoporous Mater., 2000, 38, 301-309.

24 A. Corma, U. Diaz, M. E. Domine and V. Fornes, J. Am. Chem. Soc., 2000, 122, 2804-2809.

25 W. J. Roth, P. Nachtigall, R. E. Morris and J. Cejka, Chem. Rev., 2014, 114, 4807-4837.

26 M. Mazur, M. Kubů, P. S. Wheatley and P. Eliášová, Catal. Today, DOI: 10.1016/j.cattod.2014.08.018.

27 P. Benito, M. Gregoria, S. Andreoli, G. Fornasari, S. Millefanti, F. Ospitali and S. Albonetti, Catal. Today, 2014, 235, 134-143.

28 V. Gascon, C. Marquez-Alvarez and R. M. Blanco, Appl. Catal., A, 2014, 482, 116-126.

29 G. S. Mishra, K. Machado and A. Kumar, J. Ind. Eng. Chem., 2014, 20, 2228-2235.

30 E. Perez-Mayoral, R. M. Martin-Aranda, A. J. Lopez-Peinado, P. Ballesteros, A. Zukal and J. Cejka, Top. Catal., 2009, 52, 148-152.

31 B. Van Berlo, K. Houthoofd, B. F. Sels and P. A. Jacobs, $A d v$. Synth. Catal., 2008, 350, 1949-1953.

32 H. Balcar and J. Čejka, Coord. Chem. Rev., 2013, 257, 31073124.

33 S. Gao, N. Zhao, M. Shu and S. Che, Appl. Catal., A, 2010, 388, 196-201.

34 A. Dhakshinamoorthy and H. Garcia, Chem. Soc. Rev., 2012, 41, 5262-5284.

35 B. Yuan, Y. Pan, Y. Li, B. Yin and H. Jiang, Angew. Chem., Int. Ed., 2010, 49, 4054-4058.

36 M.-J. Jin and D.-H. Lee, Angew. Chem., Int. Ed., 2010, 49, 1119-1122. 
37 V. Polshettiwar, R. Luque, A. Fihri, H. Zhu, M. Bouhrara and J.-M. Bassett, Chem. Rev., 2011, 111, 3036-3075.

38 P. D. Stevens, G. F. Li, J. D. Fan, M. Yen and Y. Gao, Chem. Commun., 2005, 4435-4437.

39 M. B. Gawande, P. S. Branco and R. S. Varma, Chem. Soc. Rev., 2013, 42, 3371-3393.

40 K. Kohler, R. G. Heidenreich, J. G. E. Krauter and M. Pietsch, Chem.-Eur. J., 2002, 8, 622-631.

41 L. Zhang, G. Wen, H. Liu, N. Wang and D. S. Su, ChemCatChem, 2014, 6, 2600-2606.

42 G. M. Scheuermann, L. Rumi, P. Steurer, W. Bannwarth and R. Muelhaupt, J. Am. Chem. Soc., 2009, 131, 8262-8270.

43 V. Farina, Adv. Synth. Catal., 2004, 346, 1553-1582.

44 S. Keesara, S. Parvathaneni, G. Dussa and M. R. Mandapati, J. Organomet. Chem., 2014, 765, 31-38.

45 E. Groppo, G. Agostini, E. Borfecchia, L. Wei, F. Giannici, G. Portale, A. Longo and C. Lamberti, J. Phys. Chem. C, 2014, 118, 8406-8415.

46 X. Wang, J. C. C. Chan, Y.-H. Tseng and S. Cheng, Microporous Mesoporous Mater., 2006, 95, 57-65.

47 M. Capka and J. Hetflejs, Collect. Czech. Chem. Commun., 1974, 39, 154-166.

48 V. Z. Sharf, A. S. Gurovets, L. P. Finn, I. B. Slinyakova, V. N. Krutii and L. K. Freidlin, Bull. Acad. Sci. USSR, Div. Chem. Sci., 1979, 28, 93-96.

49 J. M. Rosenholm, A. Penninkangas and M. Linden, Chem. Commun., 2006, 3909-3911.

50 J. M. Rosenholm and M. Linden, Chem. Mater., 2007, 19, 5023-5034.

51 G. S. Smith and S. F. Mapolie, J. Mol. Catal. A: Chem., 2004, 213, 187-192.

52 Advances in Heterocyclic Chemistry, ed. R. K. Alan, Academic Press, 2013, vol. 326.

53 Z. M. Michalska, B. Ostaszewski, J. Zientarska and J. W. Sobczak, J. Mol. Catal. A: Chem., 1998, 129, 207-218.

54 E. A. B. Kantchev, C. J. O'Brien and M. G. Organ, Angew. Chem., Int. Ed., 2007, 46, 2768-2813.

55 B. Tamami, F. Farjadian, S. Ghasemi and H. Allahyari, New J. Chem., 2013, 37, 2011-2018.

56 S. Tandukar and A. Sen, J. Mol. Catal. A: Chem., 2007, 268, 112-119.

57 E. Valeur and M. Bradley, Chem. Soc. Rev., 2009, 38, 606631.

58 A. El-Faham and F. Albericio, Chem. Rev., 2011, 111, 65576602.

59 M. Semler, J. Čejka and P. Štěpnička, Catal. Today, 2014, 227, 207-214.

60 M. Semler and P. Štěpnička, Catal. Today, DOI: 10.1016/ j.cattod.2014.06.017.

61 K. Shimizu, S. Koizumi, T. Hatamachi, H. Yoshida, S. Komai, T. Kodama and Y. Kitayama, J. Catal., 2004, 228, 141-151.

62 P. Wucher, J. B. Schwaderer and S. Mecking, ACS Catal., 2014, 4, 2672-2679.

63 T. Iwai, R. Tanaka, T. Harada and M. Sawamura, Chem.-Eur. J., 2014, 20, 1057-1065.
64 A. Fihri, M. Bouhrara, B. Nekoueishahraki, J.-M. Basset and V. Polshettiwar, Chem. Soc. Rev., 2011, 40, 5181-5203.

65 H. Zhao, G. Ding, L. Xu and M. Cai, Appl. Organomet. Chem., 2011, 25, 871-875.

66 J. Masllorens, M. Moreno-Manas, A. Pla-Quintana and A. Roglans, Org. Lett., 2003, 5, 1559-1561.

67 M. Z. Cai, Y. Z. Huang, R. H. Hu and C. S. Song, J. Mol. Catal. A: Chem., 2004, 208, 17-20.

68 M. Arpad, Chem. Rev., 2011, 111, 2251-2320.

69 G. Jayamurugan, C. P. Umesh and N. Jayaraman, J. Mol. Catal. A: Chem., 2009, 307, 142-148.

70 D. P. Catsoulacos, B. R. Steele, G. A. Heropoulos, M. MichaScrettas and C. G. Screttas, Tetrahedron Lett., 2003, 44, 4575-4578.

71 N. T. S. Phan, M. Van Der Sluys and C. W. Jones, Adv. Synth. Catal., 2006, 348, 609-679.

72 J. G. de Vries, Dalton Trans., 2006, 421-429.

73 C. S. Consorti, F. R. Flores and J. Dupont, J. Am. Chem. Soc., 2005, 127, 12054-12065.

74 F. Y. Zhao, B. M. Bhanage, M. Shirai and M. Arai, Chem.Eur. J., 2000, 6, 843-848.

75 R. L. Augustine and S. T. Oleary, J. Mol. Catal. A: Chem., 1995, 95, 277-285.

76 M. Bandini, R. Luque, V. Budarin and D. J. Macquarrie, Tetrahedron, 2005, 61, 9860-9868.

77 E. Motti, M. Rossetti, G. Bocelli and M. Catellani, J. Organomet. Chem., 2004, 689, 3741-3749.

78 H. Zhang, P. Chen and G. Liu, Angew. Chem., Int. Ed., 2014, 53, 10174-10178.

79 B. Lian, L. Zhang, G. A. Chass and D.-C. Fang, J. Org. Chem., 2013, 78, 8376-8385.

80 A. S. Singh, S. S. Shendage and J. M. Nagarkar, Tetrahedron Lett., 2013, 54, 6319-6323.

81 R. Nishio, M. Sugiura and S. Kobayashi, Chem.-Asian J., 2007, 2, 983-995.

82 N. Iranpoor, H. Firouzabadi and A. Rostami, Appl. Organomet. Chem., 2013, 27, 501-506.

83 C. Bandna, N. R. Guha, A. K. Shil, D. Sharma and P. Das, Tetrahedron Lett., 2012, 53, 5318-5322.

84 The Mizoroki-Heck Reaction, ed. M. Oestreich, John Wiley \& Sons, Ltd, 2009.

85 G. T. Crisp, Chem. Soc. Rev., 1998, 27, 427-436.

86 B. L. Shaw, New J. Chem., 1998, 22, 77-79.

87 V. P. W. Bohm and W. A. Herrmann, Chem.-Eur. J., 2001, 7, 4191-4197.

88 P. Yi, Z. Zhuangyu and H. Hongwen, J. Mol. Catal., 1990, 62, 297-306.

89 J. H. Clark, D. J. Macquarrie and E. B. Mubofu, Green Chem., 2000, 2, 53-56.

90 J. Zhou, R. Zhou, L. Mo, S. Zhao and X. Zheng, J. Mol. Catal. A: Chem., 2002, 178, 289-292.

91 S. F. Zhao, R. X. Zhou and X. M. Zheng, J. Mol. Catal. A: Chem., 2004, 211, 139-142.

92 H. Li, L. Wang and P. Li, Synthesis, 2007, 1635-1642.

93 J. Demel, Sujandi, S.-E. Park, J. Čejka and P. Štěpnička, J. Mol. Catal. A: Chem., 2009, 302, 28-35. 
94 J. Demel, M. Lamač, J. Čejka and P. Štěpnička, ChemSusChem, 2009, 2, 442-451.

95 P. Wang, Q. Lu and J. Li, Mater. Res. Bull., 2010, 45, 129-134.

96 J. Demel, J. Čejka and P. Štěpnička, J. Mol. Catal. A: Chem., 2010, 329, 13-20.

97 S. Martinez, M. Moreno-Manas, A. Vallribera, U. Schubert, A. Roig and E. Molins, New J. Chem., 2006, 30, 1093-1097.

98 S. Mandal, D. Roy, R. V. Chaudhari and M. Sastry, Chem. Mater., 2004, 16, 3714-3724.

99 G. Martra, L. Bertinetti, C. Gerbaldi, R. Maggi, G. Sartori and S. Coluccia, Catal. Lett., 2009, 132, 50-57.

100 C. M. Crudden, M. Sateesh and R. Lewis, J. Am. Chem. Soc., 2005, 127, 10045-10050.

101 J. M. Richardson and C. W. Jones, J. Catal., 2007, 251, 8093.

102 K. McEleney, C. M. Crudden and J. H. Horton, J. Phys. Chem. C, 2009, 113, 1901-1907.

103 C. M. Crudden, K. McEleney, S. L. MacQuarrie, A. Blanc, M. Sateesh and J. D. Webb, Pure Appl. Chem., 2007, 79, 247-260.

104 Q. Xu and M. Cai, React. Funct. Polym., 2007, 67, 515-521.

105 R.-X. Zhou, J.-M. Zhou and X.-M. Zheng, React. Kinet. Catal. Lett., 2005, 87, 157-163.

106 M. Cai, Q. Xu and J. Jiang, J. Mol. Catal. A: Chem., 2006, 260, 190-196.

107 S. Niembro, A. Shafir, A. Vallribera and R. Alibés, Org. Lett., 2008, 10, 3215-3218.

108 S. Niembro, A. Shafir and A. Vallribera, ARKIVOC, 2010, 181-190.

109 M. Cai and J. Sha, Catal. Commun., 2007, 8, 1691-1696.

110 G. Singh, S. Bali and A. K. Singh, Polyhedron, 2007, 26, 897903.

111 K. Yu, W. Sommer, M. Weck and C. W. Jones, J. Catal., 2004, 226, 101-110.

112 K. Yu, W. Sommer, J. M. Richardson, M. Weck and C. W. Jones, Adv. Synth. Catal., 2005, 347, 161-171.

113 W. J. Sommer, K. Yu, J. S. Sears, Y. Ji, X. Zheng, R. J. Davis, C. D. Sherrill, C. W. Jones and M. Weck, Organometallics, 2005, 24, 4351-4361.

114 Ö. Aksın, H. Türkmen, L. Artok, B. Çetinkaya, C. Ni, O. Büyükgüngör and E. Özkal, J. Organomet. Chem., 2006, 691, 3027-3036.

115 B. Karimi and D. Enders, Org. Lett., 2006, 8, 1237-1240.

116 A. Suzuki, Chem. Commun., 2005, 4759-4763.

117 A. J. J. Lennox and G. C. Lloyd-Jones, Chem. Soc. Rev., 2014, 43, 412-443.

118 E. B. Mubofu, J. H. Clark and D. J. Macquarrie, Green Chem., 2001, 3, 23-25.

119 S. Paul and J. H. Clark, J. Mol. Catal. A: Chem., 2004, 215, 107-111.

120 S. Bhunia, R. Sen and S. Koner, Inorg. Chim. Acta, 2010, 363, 3993-3999.

121 H. Zhao, G. Ding, L. Xu and M. Cai, Appl. Organomet. Chem., 2011, 25, 871-875.

122 O. Vassylyev, J. Chen, A. P. Panarello and J. G. Khinast, Tetrahedron Lett., 2005, 46, 6865-6869.
123 M. Trilla, G. Borja, R. Pleixats, M. W. C. Man, C. Bied and J. J. E. Moreau, Adv. Synth. Catal., 2008, 350, 2566-2574.

124 H. Gruber-Woelfler, P. F. Radaschitz, P. W. Feenstra, W. Haas and J. G. Khinast, J. Catal., 2012, 286, 30-40.

125 E. Tyrrell, L. Whiteman and N. Williams, J. Organomet. Chem., 2011, 696, 3465-3472.

126 K. Gude and R. Narayanan, J. Phys. Chem. C, 2011, 115, 12716-12725.

127 N. Fukaya, M. Ueda, S.-y. Onozawa, K. K. Bando, T. Miyaji, Y. Takagi, T. Sakakura and H. Yasuda, J. Mol. Catal. A: Chem., 2011, 342-343, 58-66.

128 N. J. S. Costa, P. K. Kiyohara, A. L. Monteiro, Y. Coppel, K. Philippot and L. M. Rossi, J. Catal., 2010, 276, 382-389.

129 K. Dhara, K. Sarkar, D. Srimani, S. K. Saha, P. Chattopadhyay and A. Bhaumik, Dalton Trans., 2010, 6395-6402.

130 S.-M. Lee, H.-J. Yoon, J.-H. Kim, W.-J. Chung and Y.-S. Lee, Pure Appl. Chem., 2007, 79, 1553-1559.

131 J. D. Webb, S. MacQuarrie, K. McEleney and C. M. Crudden, J. Catal., 2007, 252, 97-109.

132 B. Nohair, S. MacQuarrie, C. M. Crudden and S. Kaliaguine, J. Phys. Chem. C, 2008, 112, 6065-6072.

133 M. Al-Hashimi, A. Qazi, A. C. Sullivan and J. R. H. Wilson, J. Mol. Catal. A: Chem., 2007, 278, 160-164.

134 M. Al-Hashimi, A. C. Sullivan and J. R. H. Wilson, J. Mol. Catal. A: Chem., 2007, 273, 298-302.

135 X. Feng, M. Yan, T. Zhang, Y. Liu and M. Bao, Green Chem., 2010, 12, 1758-1766.

136 M. Cai, J. Sha and Q. Xu, J. Mol. Catal. A: Chem., 2007, 268, 82-86.

137 M. Cai, G. Zheng, L. Zha and J. Peng, Eur. J. Org. Chem., 2009, 2009, 1585-1591.

138 R. Sayah, K. Glegoła, E. Framery and V. Dufaud, Adv. Synth. Catal., 2007, 349, 373-381.

139 A. Leyva, H. García and A. Corma, Tetrahedron, 2007, 63, 7097-7111.

140 D.-H. Lee, M. Choi, B.-W. Yu, R. Ryoo, A. Taher, S. Hossain and M.-J. Jin, Adv. Synth. Catal., 2009, 351, 2912-2920.

141 R. Chinchilla and C. Nájera, Chem. Rev., 2007, 107, 874-922.

142 L. Brandsma, Synthesis of Acetylenes, Allenes and Cumulenes, Academic Press, Oxford, 2004.

143 R. R. Tykwinski, Angew. Chem., Int. Ed., 2003, 42, 15661568.

144 E.-i. Negishi and L. Anastasia, Chem. Rev., 2003, 103, 19792018.

145 K. Sonogashira, in Handbook of Organopalladium Chemistry for Organic Synthesis, John Wiley \& Sons, Inc., 2003, pp. 493-529.

146 K. Sonogashira, J. Organomet. Chem., 2002, 653, 46-49.

147 P.-H. Li and L. Wang, Adv. Synth. Catal., 2006, 348, 681-685.

148 K. K. Sharma, A. V. Biradar, S. Das and T. Asefa, Eur. J. Inorg. Chem., 2011, 2011, 3174-3182.

149 K. Komura, H. Nakamura and Y. Sugi, J. Mol. Catal. A: Chem., 2008, 293, 72-78.

150 M. Trilla, R. Pleixats, M. W. C. Man, C. Bied and J. J. E. Moreau, Adv. Synth. Catal., 2008, 350, 577-590. 
151 S. El Hankari, A. El Kadib, A. Finiels, A. Bouhaouss, J. J. E. Moreau, C. M. Crudden, D. Brunel and P. Hesemann, Chem.-Eur. J., 2011, 17, 8984-8994.

152 K. Okuyama, J. Sugiyama, R. Nagahata, M. Asai, M. Ueda and K. Takeuchi, J. Mol. Catal. A: Chem., 2003, 203, 21-27.

153 H. Y. Song, E. D. Park and J. S. Lee, J. Mol. Catal. A: Chem., 2000, 154, 243-250.

154 G. Fan, J. Huang, Z. Li, T. Li and G. Li, J. Mol. Catal. A: Chem., 2007, 267, 34-40.

155 M. R. Didgikar, D. Roy, S. P. Gupte, S. S. Joshi and R. V. Chaudhari, Ind. Eng. Chem. Res., 2010, 49, 1027-1032.

156 S. Fukuoka, M. Chono and M. Kohno, J. Org. Chem., 1984, 49, 1458-1460.

157 S. P. Gupte and R. V. Chaudhari, Ind. Eng. Chem. Res., 1992, 31, 2069-2074.

158 F. Shi and Y. Q. Deng, J. Catal., 2002, 211, 548-551.

159 B. R. Sarkar and R. V. Chaudhari, Catal. Today, 2012, 198, 154-173.

160 M. Lagasi and P. Moggi, J. Mol. Catal. A: Chem., 2002, 182183, 61-72.

161 M. Genelot, N. Villandier, A. Bendjeriou, P. Jaithong, L. Djakovitch and V. Dufaud, Catal. Sci. Technol., 2012, 2, 1886-1893.

162 S. M. Lu and H. Alper, J. Am. Chem. Soc., 2005, 127, 1477614784.

163 M. Cai, J. Peng, W. Hao and G. Ding, Green Chem., 2011, 13, 190-196.

164 W. Hao, J. Sha, S. Sheng and M. Cai, J. Mol. Catal. A: Chem., 2009, 298, 94-98.

165 C. P. Vinod, K. Wilson and A. F. Lee, J. Chem. Technol. Biotechnol., 2011, 86, 161-171.

166 Y. Uozumi and Y. M. A. Yamada, Chem. Rec., 2009, 9, 51-65.

167 J. Muzart, Tetrahedron, 2003, 59, 5789-5816.

168 J. H. Clark, Green Chem., 1999, 1, 1-8.

169 T. Mallat and A. Baiker, Chem. Rev., 2004, 104, 3037-3058.

170 C. M. A. Parlett, L. J. Durndell, A. Machado, G. Cibin, D. W. Bruce, N. S. Hondow, K. Wilson and A. F. Lee, Catal. Today, 2014, 229, 46-55.

171 C. M. A. Parlett, D. W. Bruce, N. S. Hondow, A. F. Lee and K. Wilson, ACS Catal., 2011, 1, 636-640.

172 C. M. A. Parlett, D. W. Bruce, N. S. Hondow, M. A. Newton, A. F. Lee and K. Wilson, ChemCatChem, 2013, 5, 939-950.

173 M. S. Holm, E. Taarning, K. Egeblad and C. H. Christensen, Catal. Today, 2011, 168, 3-16.

174 Y. Chen, H. Lim, Q. Tang, Y. Gao, T. Sun, Q. Yan and Y. Yang, Appl. Catal., A, 2010, 380, 55-65.

175 Z. Ma, H. Yang, Y. Qin, Y. Hao and G. Li, J. Mol. Catal. A: Chem., 2010, 331, 78-85.

176 Y. Shi, H. Yang, X. Zhao, T. Cao, J. Chen, W. Zhu, Y. Yu and Z. Hou, Catal. Commun., 2012, 18, 142-146.

177 X. Yang, C. Huang, Z. Fu, H. Song, S. Liao, Y. Su, L. Du and X. Li, Appl. Catal., B, 2013, 140, 419-425.

178 Y. Chen, Z. Guo, T. Chen and Y. Yang, J. Catal., 2010, 275, 11-24.

179 C. M. A. Parlett, P. Keshwalla, S. G. Wainwright, D. W. Bruce, N. S. Hondow, K. Wilson and A. F. Lee, ACS Catal., 2013, 3, 2122-2129.
180 B. Karimi, S. Abedi, J. H. Clark and V. Budarin, Angew. Chem., Int. Ed., 2006, 45, 4776-4779.

181 B. Karimi, A. Zamani, S. Abedi and J. H. Clark, Green Chem., 2009, 11, 109-119.

182 Z. Hou, N. Theyssen, A. Brinkmann, K. V. Klementiev, W. Grünert, M. Bühl, W. Schmidt, B. Spliethoff, B. Tesche, C. Weidenthaler and W. Leitner, J. Catal., 2008, 258, 315-323.

183 H. Yang, X. Han, Z. Ma, R. Wang, J. Liu and X. Ji, Green Chem., 2010, 12, 441-451.

184 H. Yang, Z. Ma, Y. Qing, G. Xie, J. Gao, L. zhang, J. Gao and L. du, Appl. Catal., A, 2010, 382, 312-321.

185 B. Chen, U. Dingerdissen, J. G. E. Krauter, H. Rotgerink, K. Mobus, D. J. Ostgard, P. Panster, T. H. Riermeier, S. Seebald, T. Tacke and H. Trauthwein, Appl. Catal., A, 2005, 280, 17-46.

186 K. Nomura, J. Mol. Catal. A: Chem., 1998, 130, 1-28.

187 N. Maity, P. R. Rajamohanan, S. Ganapathy, C. S. Gopinath, S. Bhaduri and G. K. Lahiri, J. Phys. Chem. C, 2008, 112, 9428-9433.

188 A. Indra, P. R. Rajamohanan, C. S. Gopinath, S. Bhaduri and G. K. Lahiri, Appl. Catal., A, 2011, 399, 117-125.

189 S. M. El-Sheikh, A. A. Ismail and J. F. Al-Sharab, New J. Chem., 2013, 37, 2399-2407.

190 D. K. Yi, S. S. Lee and J. Y. Ying, Chem. Mater., 2006, 18, 2459-2461.

191 P. Wang, F. Zhang, Y. Long, M. Xie, R. Li and J. Ma, Catal. Sci. Technol., 2013, 3, 1618-1624.

192 F. Zhang, J. Jin, X. Zhong, S. Li, J. Niu, R. Li and J. Ma, Green Chem., 2011, 13, 1238-1243.

193 A. Qazi and A. Sullivan, Dalton Trans., 2011, 10637-10642.

194 Y. Takenaka, T. Kiyosu, G. Mori, J.-C. Choi, T. Sakakura and H. Yasuda, Catal. Today, 2011, 164, 580-584.

195 J. Li, X.-Y. Shi, Y.-Y. Bi, J.-F. Wei and Z.-G. Chen, ACS Catal., 2011, 1, 657-664.

196 X. B. Yu, M. H. Wang and H. X. Li, Appl. Catal., A, 2000, 202, 17-22.

197 X. L. Xi, Y. L. Liu, J. Shi and S. K. Cao, J. Mol. Catal. A: Chem., 2003, 192, 1-7.

198 I. D. Gridnev, T. Imamoto, G. Hoge, M. Kouchi and H. Takahashi, J. Am. Chem. Soc., 2008, 130, 2560-2572.

199 M. Crespo-Quesada, F. Cardenas-Lizana, A.-L. Dessimoz and L. Kiwi-Minsker, ACS Catal., 2012, 2, 1773-1786.

200 A. Molnar, A. Sarkany and M. Varga,J. Mol. Catal. A: Chem., 2001, 173, 185-221.

201 S. Shimazu, N. Baba, N. Ichikuni and T. Uematsu, J. Mol. Catal. A: Chem., 2002, 182-183, 343-350.

202 Y. Jiang and Q. Gao, J. Am. Chem. Soc., 2005, 128, 716-717.

203 T. Wu, T. Jiang, B. Hu, B. Han, J. He and X. Zhou, Green Chem., 2009, 11, 798-803.

204 Y. J. Jiang and Q. M. Gao, J. Am. Chem. Soc., 2006, 128, 716717.

205 S. Kidambi, J. H. Dai, J. Li and M. L. Bruening, J. Am. Chem. Soc., 2004, 126, 2658-2659.

206 G. Liu, M. Hou, T. Wu, T. Jiang, H. Fan, G. Yang and B. Han, Phys. Chem. Chem. Phys., 2011, 13, 2062-2068. 
207 N. Erathodiyil, S. Ooi, A. M. Seayad, Y. Han, S. S. Lee and J. Y. Ying, Chem.-Eur. J., 2008, 14, 3118-3125.

208 H. Gao and R. J. Angelici, J. Mol. Catal. A: Chem., 1999, 149, 63-74.

209 H. Gao and R. J. Angelici, J. Mol. Catal. A: Chem., 1999, 145, 83-94.

210 G. X. Pei, X. Y. Liu, A. Wang, L. Li, Y. Huang, T. Zhang, J. W. Lee, B. W. L. Jang and C.-Y. Mou, New J. Chem., 2014, 38, 2043-2051.

211 W. Long, N. A. Brunelli, S. A. Didas, E. W. Ping and C. W. Jones, ACS Catal., 2013, 3, 1700-1708.

212 M. Lim, K. A. De Castro, S. Oh, K. Lee, Y.-W. Chang, H. Kim and H. Rhee, Appl. Organomet. Chem., 2011, 25, 1-8.

213 M. A. Nesterov, M. M. Chizhova and V. Z. Sharf, Bull. Acad. Sci. USSR, Div. Chem. Sci., 1986, 35, 1742.

214 H. Yang, H. Gao and R. J. Angelici, Organometallics, 1999, 18, 2285-2287.

215 M. Gregori, P. Benito, G. Fornasari, M. Migani, S. Millefanti, F. Ospitali and S. Albonetti, Microporous Mesoporous Mater., 2014, 190, 1-9.

216 P. Šť̌pnička, M. Semler, J. Demel, A. Zukal and J. Čejka, J. Mol. Catal. A: Chem., 2011, 341, 97-102.

217 H. Zhao, J. Peng, R. Xiao, W. Hao and M.-Z. Cai, J. Organomet. Chem., 2011, 696, 2030-2034.

218 H. Li, L. Wang, M. Yang and Y. Qi, Catal. Commun., 2012, 17, 179-183.

219 H. Li, M. Yang and Q. Pu, Microporous Mesoporous Mater., 2012, 148, 166-173.

220 F.-Y. Tsai, B.-N. Lin, M.-J. Chen, C.-Y. Mou and S.-T. Liu, Tetrahedron, 2007, 63, 4304-4309.

221 J.-Y. Chen, S.-C. Chen, Y.-J. Tang, C.-Y. Mou and F.-Y. Tsai, J. Mol. Catal. A: Chem., 2009, 307, 88-92.

222 S. C. Bourque, F. Maltais, W.-J. Xiao, O. Tardif, H. Alper, P. Arya and L. E. Manzer, J. Am. Chem. Soc., 1999, 121, 3035-3038.

223 J. P. K. Reynhardt, Y. Yang, A. Sayari and H. Alper, Chem. Mater., 2004, 16, 4095-4102.

224 D. A. Tomalia, H. Baker, J. Dewald, M. Hall, G. Kallos, S. Martin, J. Roeck, J. Ryder and P. Smith, Polym. J., 1985, 17, 117-132.

225 J. P. K. Reynhardt and H. Alper, J. Org. Chem., 2003, 68, 8353-8360.
226 R. Chanthateyanonth and H. Alper, J. Mol. Catal. A: Chem., 2003, 201, 23-31.

227 F. Zhang, G. Liu, W. He, H. Yin, X. Yang, H. Li, J. Zhu, H. Li and Y. Lu, Adv. Funct. Mater., 2008, 18, 3590-3597.

228 J. Huang, F. Zhu, W. He, F. Zhang, W. Wang and H. Li, J. Am. Chem. Soc., 2010, 132, 1492-1493.

229 J. Huang and F. Zhang, Appl. Organomet. Chem., 2010, 24, 767-773.

230 J. Huang, M. Wang, S. Zhang, B. Hu and H. Li, J. Phys. Chem. C, 2011, 115, 22514-22522.

231 Q. Hu, J. E. Hampsey, N. Jiang, C. Li and Y. Lu, Chem. Mater., 2005, 17, 1561-1569.

232 V. Polshettiwar, P. Hesemann and J. J. E. Moreau, Tetrahedron, 2007, 63, 6784-6790.

233 H. Zhao, G. Zheng, W. Hao and M. Cai, Appl. Organomet. Chem., 2010, 24, 92-98.

234 E. W. Ping, R. Wallace, J. Pierson, T. F. Fuller and C. W. Jones, Microporous Mesoporous Mater., 2010, 132, 174-180.

235 S. Park, J. Jung, J. Seo, T. Kim, Y.-M. Chung, S.-H. Oh and I. Song, Catal. Lett., 2009, 130, 604-607.

236 S. Park, S.-H. Baeck, T. J. Kim, Y.-M. Chung, S.-H. Oh and I. K. Song, J. Mol. Catal. A: Chem., 2010, 319, 98-107.

237 S. Park, T. Kim, Y.-M. Chung, S.-H. Oh and I. Song, Korean J. Chem. Eng., 2011, 28, 1359-1363.

238 N. Batail, A. Bendjeriou, L. Djakovitch and V. Dufaud, Appl. Catal., A, 2010, 388, 179-187.

239 A. J. Sandee, D. Dimitrijevic, R. J. van Haaren, J. N. H. Reek, P. C. J. Kamer and P. W. N. M. van Leeuwen, J. Mol. Catal. A: Chem., 2002, 182-183, 309-317.

240 B. F. G. Johnson, S. A. Raynor, D. S. Shephard, T. Mashmeyer, T. Mashmeyer, J. Meurig Thomas, G. Sankar, S. Bromley, R. Oldroyd, L. Gladden and M. D. Mantle, Chem. Commun., 1999, 1167-1168.

241 T. Hayashi, T. Mise, M. Fukushima, M. Kagotani, N. Nagashima, Y. Hamada, A. Matsumoto, S. Kawakami, M. Konishi, K. Yamamoto and M. Kumada, Bull. Chem. Soc. Jpn., 1980, 53, 1138-1151.

242 N. C. Mehendale, J. R. A. Sietsma, K. P. de Jong, C. A. van Walree, R. J. M. K. Gebbink and G. van Koten, Adv. Synth. Catal., 2007, 349, 2619-2630. 